\title{
Melt inclusion constraints on mantle carbon heterogeneity within an individual mantle plume and at the global scale
}

\author{
Simon Matthews ${ }^{\mathrm{a}, *}$, Oliver Shorttle ${ }^{\mathrm{a}, \mathrm{b}}$, John Maclennan ${ }^{\mathrm{a}}$, John F. Rudge ${ }^{\mathrm{a}}$ \\ ${ }^{a}$ Department of Earth Sciences, University of Cambridge, Downing Street, Cambridge, CB2 3EQ, UK. \\ ${ }^{b}$ Institute of Astronomy, University of Cambridge, Madingley Road, Cambridge, CB3 OHA, UK.
}

\begin{abstract}
The Earth's mantle holds more carbon than its oceans, atmosphere and continents combined, yet the distribution of carbon within the mantle remains uncertain. Global variations in the carbon content of the depleted mantle have been inferred from carbon-trace element systematics of ultra-depleted mid-ocean ridge glasses and melt inclusions, though the origin of mantle carbon variability remains uncertain. A variety of observations suggest that the mantle plumes underlying ocean islands have high bulk carbon contents, but the characterisation of individual mantle plume components has not been possible.

We supplement the existing melt inclusion data from Iceland with four new datasets, significantly enhancing the spatial and geochemical coverage. Within the combined dataset there is significant variation in melt inclusion $\mathrm{CO}_{2} / \mathrm{Ba}$ ratio, which is tightly correlated with trace element enrichment. The trends in $\mathrm{CO}_{2} / \mathrm{Ba}-\mathrm{Ba}$ space displayed by our new data coincide with the same trends in data compiled from global ocean islands and mid-ocean ridges, forming a global array. The overall structure of the global $\mathrm{CO}_{2} / \mathrm{Ba}$ array is not a property of the source, instead controlled by $\mathrm{CO}_{2}$ degassing before melt inclusion entrapment, and $\mathrm{CO}_{2}$ loss by decrepitation following inclusion entrapment.

The position of melt inclusion datasets within the global array allows us to filter out inclusions likely to have undergone decrepitation. Providing earlier $\mathrm{CO}_{2}$ degassing and magma mixing have not destroyed the mantle signal, the remaining inclusions may preserve mantle $\mathrm{CO}_{2} / \mathrm{Ba}$ values. Using the observed covariation of the filtered $\mathrm{CO}_{2} / \mathrm{Ba}$ ratio with radiogenic isotope tracers of mantle source, we find $\mathrm{CO}_{2}$ concentrations in the Icelandic depleted mantle of $102_{-27}^{+53}$ ppmw, typical of mantle underlying the mid-ocean ridge system, and high $\mathrm{CO}_{2}$ concentrations of $2.2_{-1.5}^{+3.8} \mathrm{wt} \%$ associated with the high ${ }^{3} \mathrm{He} /{ }^{4} \mathrm{He}$ component of the Iceland plume. However, source and process are difficult to deconvolve for the eruptions most sensitive to enriched, or recycled, mantle components; the presently available data is consistent with recycled material being either enriched or depleted in carbon.

Extending our approach globally, we find no systematic variation in $\mathrm{CO}_{2} / \mathrm{Ba}$ or $\mathrm{CO}_{2} / \mathrm{Nb}$ with enrichment (in the absence of a primordial mantle contribution). The lack of global co-variation suggests mechanisms recycling $\mathrm{CO}_{2}$ from the surface into the convecting mantle are decoupled from those recycling most trace elements. However, the variation of $\mathrm{CO}_{2} / \mathrm{Nb}$ with $\mathrm{Ba} / \mathrm{Nb}$ suggests $\mathrm{Ba}$ may behave similarly to $\mathrm{CO}_{2}$ during recycling.
\end{abstract}

Keywords: Mantle, Carbon, Heterogeneity, Iceland, Melt Inclusions, Recycling, Primordial

\section{Introduction}

The majority of Earth's carbon, that has not been sequestered to the core, resides in the mantle (Dasgupta and Hirschmann, 2010; Kelemen and

\footnotetext{
* Now at Department of Earth and Planetary Sciences, Johns Hopkins University, Baltimore, MD 21218, USA. simonmatthews@jhu.edu
}

Preprint submitted to GCA
Manning, 2015). Carbon exchange between the surface and deep occurs principally by volcanic outgassing and subduction of oceanic plates. Since the advent of plate tectonics these processes have shaped the inventories of carbon within the surface and mantle reservoirs. However, the magnitude of these fluxes, both at the present day and in 
the Earth's deep past, remain largely uncertain. A great deal of this uncertainty is associated with the efficiency of carbon recycling in subducting slabs; thermodynamic modelling suggests slab decarbonation should be limited in most subduction zones (Kerrick and Connolly, 2001), but the infiltration of hydrous fluids may mobilise carbonate from the subducting plate (Kelemen and Manning, 2015). Hirschmann (2018) placed empirical bounds on recycling efficiency by comparing the $\mathrm{CO}_{2} / \mathrm{Ba}$ ratios of the Earth's exosphere and upper mantle and found that at least $25 \%$, and probably much more, of the carbon outgassed to the exosphere must have been returned to the mantle via subduction.

An alternative, but complementary, approach to constraining $\mathrm{CO}_{2}$ recycling efficiency is to estimate the amount of carbon within recycled mantle domains where they are sampled at ocean islands. $\mathrm{CO}_{2}$-noble gas systematics of fluid inclusions in material erupted in Hawaii and La Réunion Island indicate their mantle sources are carbon rich (Trull et al., 1993; Boudoire et al., 2018), which is further supported by models that couple $\mathrm{CO}_{2}$ emission rates with magma supply rates at Hawaii (Anderson and Poland, 2017) and high $\mathrm{CO}_{2}$ contents of primitive melts (Tucker et al., 2019). However, both Hawaii and La Réunion are underlain by mantle plumes transporting primordial (high ${ }^{3} \mathrm{He} /{ }^{4} \mathrm{He}$ ) mantle, which may contain high concentrations of carbon (Miller et al., 2019). In order to assess the efficiency of carbon recycling it is necessary to deconvolve the contributions of carbon from recycled and primordial mantle domains to volcanic outgassing.

Progress in identifying mantle carbon variability has been hampered by its tendency to exsolve from magmas into a $\mathrm{CO}_{2}$ vapour phase. The solubility of $\mathrm{CO}_{2}$ in basaltic melts is minimal at the low pressures of eruption (Stolper and Holloway, 1988), with the consequence that considerable $\mathrm{CO}_{2}$ will have been lost by $\mathrm{CO}_{2}$ vapour exsolution (degassing) in all but the most $\mathrm{CO}_{2}$ poor melts.

\subsection{Estimating mantle carbon}

A number of approaches have been taken to circumvent the overprint of degassing on the mantle $\mathrm{CO}_{2}$ signals. Rare ultra-depleted glasses erupted in oceanic fracture zones often contain sufficiently low concentrations of $\mathrm{CO}_{2}$ that they are undersaturated in $\mathrm{CO}_{2}$ vapour at the pressure of eruption. However, Matthews et al. (2017) suggested these magmas formed by mixing of trace-element and
$\mathrm{CO}_{2}$ enriched melts that are partially degassed with trace-element and $\mathrm{CO}_{2}$ depleted melts; with the significant $\mathrm{CO}_{2}$ vapour undersaturation of the depleted melts conferring $\mathrm{CO}_{2}$ undersaturation onto the mixed magma. This process is difficult to definitively identify and could lead to underestimates of mantle $\mathrm{CO}_{2}$ concentrations. Occasionally, extremely trace-element enriched mid-ocean ridge basalt (MORB) glasses retain gas rich vesicles, which may contain the full budget of $\mathrm{CO}_{2}$ and other volatiles that exsolved from the magma (Cartigny et al., 2008; Jones et al., 2019). It is again unclear whether these enriched magmas lost $\mathrm{CO}_{2}$ deeper within the crust, before beginning to retain vesicles. Furthermore, the MORB glass datasets only provide information about the mantle underlying the mid-ocean ridge system and are therefore biased towards characterising the depleted upper mantle.

Another approach uses melt inclusions, tiny droplets of magma trapped within crystals as they grow at depth within the crust. The elastic strength of the host crystals prevents decompression of the inclusion to the pressure of the surrounding melt, potentially allowing the melt to remain undersaturated in $\mathrm{CO}_{2}$ vapour. Not only are melt inclusions ubiquitous in MORB, but they can also be readily found in ocean island basalt (OIB). Melt inclusions also offer an unrivalled view of the earliest stages of magma evolution, when the diversity of melt chemistry generated by near-fractional melting is still partially preserved (Sobolev and Shimizu, 1993). However, the $\mathrm{CO}_{2}$ budget of melt inclusions remains susceptible to the same degassing and mixing processes as the ultra-depleted glasses. Postentrapment $\mathrm{CO}_{2}$ loss via decrepitation of the host crystals is also likely to occur (Maclennan, 2017).

\subsection{Ratios of $\mathrm{CO}_{2}$ and trace-element concentra- tions}

One process affecting carbon that it may be possible to successfully control for is melting. Ratios of $\mathrm{CO}_{2}$ to $\mathrm{Ba}$ or $\mathrm{Nb}$ concentrations have been used to achieve this (Saal et al., 2002; Le Voyer et al., 2017; Hauri et al., 2018; Michael and Graham, 2015; Shimizu et al., 2016; Tucker et al., 2019; Shimizu et al., 2019; Miller et al., 2019), since $\mathrm{CO}_{2}, \mathrm{Ba}$, and $\mathrm{Nb}$ partition similarly during mantle melting (Saal et al., 2002; Rosenthal et al., 2015). Given this similarity in partitioning behaviour, it should be expected that pre-degassing magmatic values of $\mathrm{CO}_{2} / \mathrm{Ba}$ and $\mathrm{CO}_{2} / \mathrm{Nb}$ will not be fractionated from 
their mantle sources; the exception to this being that even small differences between the partition coefficients can cause large variations in the $\mathrm{CO}_{2} / \mathrm{Ba}$ and $\mathrm{CO}_{2} / \mathrm{Nb}$ of instantaneous fractional melts extracted from a previously depleted source (Rosenthal et al., 2015).

A number of previous studies (Saal et al., 2002; Le Voyer et al., 2017; Hauri et al., 2018) are predicated upon correlations between $\mathrm{CO}_{2}$ and $\mathrm{Ba}$ or $\mathrm{Nb}$ indicating a lack of any fractionation between $\mathrm{CO}_{2}$ and the incompatible trace elements, including the absence of any $\mathrm{CO}_{2}$ degassing prior to, or after, inclusion entrapment. However, Matthews et al. (2017) demonstrated that such correlations are also a natural consequence of degassing and mixing of compositionally diverse near-fractional mantle melts, and such a process can explain the increasing variation in $\mathrm{CO}_{2} / \mathrm{Ba}$ with $\mathrm{Ba}$ concentration that many datasets exhibit.

Magma mixing is common in magmatic systems (Sobolev, 1996; Maclennan, 2008a; Shorttle, 2015; Shorttle et al., 2016), and the most $\mathrm{CO}_{2}$ rich fractional melts are expected to saturate in $\mathrm{CO}_{2}$ vapour at pressures within, or below, the crust (Dixon et al., 1995). Though the degassing and mixing process causes the average value of $\mathrm{CO}_{2} / \mathrm{Ba}$ within a dataset to be controlled primarily by the pressure of degassing, the maximum values seen in a dataset may still record the mantle value (or are at least a minimum estimate of the mantle value). Datasets that do not exhibit correlations likely have a more complex multi-stage degassing history, making them less reliable records of mantle $\mathrm{CO}_{2} / \mathrm{Ba}$ ratios.

Shimizu et al. (2019) recently demonstrated that not all melt inclusion datasets require a partialdegassing and mixing process to explain their $\mathrm{CO}_{2}-$ trace element systematics. For inclusions from the Siqueiros and Garrett transform faults, Shimizu et al. (2019) showed that the covariance of $\mathrm{CO}_{2}$ with a broad suite of trace elements is compatible with the trapped melts having a single mantlederived $\mathrm{CO}_{2} / \mathrm{Ba}$ ratio for variable $\mathrm{Ba}$ concentration. The observed variability in $\mathrm{CO}_{2} / \mathrm{Ba}$ and $\mathrm{CO}_{2} / \mathrm{Nb}$ ratios arises from analytical imprecision. However, partially degassed datasets can also give rise to melt inclusions with a single $\mathrm{CO}_{2} / \mathrm{Ba}$ ratio at variable $\mathrm{Ba}$ concentration. If the trace-element and $\mathrm{CO}_{2}$ enriched melts degas, but are then efficiently homogenised, a single enriched mixing endmember is produced, with a $\mathrm{CO}_{2} / \mathrm{Ba}$ ratio lower than the mantle value (Matthews et al., 2017, Appendix A).
When mixed with extremely trace-element and $\mathrm{CO}_{2}$ depleted melts, a binary mixing array in $\mathrm{CO}_{2}-\mathrm{Ba}$ space will be generated with each melt having an identical $\mathrm{CO}_{2} / \mathrm{Ba}$ ratio. In this scenario, the mean $\mathrm{CO}_{2} / \mathrm{Ba}$ ratio of the datasets would then be only a minimum bound on the mantle value. The implications and likelihood of such a process for the Siqueiros and Garrett datasets are discussed in Section 5.7.

To understand what $\mathrm{CO}_{2} / \mathrm{Ba}$ and $\mathrm{CO}_{2} / \mathrm{Nb}$ ratios tell us about mantle carbon heterogeneity we need to consider how these elements are transferred to the melt. During mantle melting, the residue is likely to be completely depleted of $\mathrm{CO}_{2}$ after only a few percent melting, either by the formation of carbonatitic or carbonated-silicate melts if a carbon phase is present (Dasgupta and Hirschmann, 2010), or by virtue of the incompatibility of $\mathrm{CO}_{2}$ in silicate minerals (Saal et al., 2002; Rosenthal et al., 2015). Even refractory mantle lithologies are likely to have entirely lost their carbon to a melt phase long before silicate melting begins. Since such low-degree melts have a vanishingly small chance of escaping mixing during transport, we assume that melts in one location will not preserve the variable $\mathrm{CO}_{2} / \mathrm{Ba}$ and $\mathrm{CO}_{2} / \mathrm{Nb}$ ratios of small-scale heterogeneities, but instead will inherit an average value. Larger scale variations in the relative proportions of small-scale heterogeneities may allow the relative contributions of different mantle components to the $\mathrm{CO}_{2}$ budget of the magma to be deconvolved.

\subsection{Identifying mantle $\mathrm{CO}_{2}$ heterogeneity}

In this contribution we seek to assess the presence of carbon rich mantle reservoirs in the Earth. In order to deconvolve the signals of $\mathrm{CO}_{2}$ degassing and mantle heterogeneity, a large number of melt inclusions from eruptions sampling a diversity of mantle sources need to be analysed for both their trace element and $\mathrm{CO}_{2}$ concentrations. We approach this by considering mantle carbon heterogeneity on the scale of both a single well sampled mantle plume (Iceland), and a global scale with the more sparsely sampled mid-ocean ridges and ocean islands. Iceland offers an excellent opportunity for studying carbon heterogeneity within a single mantle plume due to the large number of previous melt inclusion studies (Hauri et al., 2018; Hartley et al., 2014; Neave et al., 2014; Bali et al., 2018; Schipper et al., 2016; Miller et al., 2019), which we supplement with four new datasets (Sections 2 and Section 3.1). 
Comparisons between the $\mathrm{CO}_{2}$-trace element systematics present within the Iceland melt inclusion compilation and the global compilation enable us to make a new assessment of the effects of crustal storage and melt inclusion decrepitation (Section 4). Though this secondary crustal processing signal dominates the global $\mathrm{CO}_{2} / \mathrm{Ba}$ and $\mathrm{CO}_{2} / \mathrm{Nb}$ arrays, in Section 5 we demonstrate that a signal of mantle source $\mathrm{CO}_{2}$ heterogeneity still remains in the Iceland compilation. By inversion of a three component mixing model (Section 5.4) we estimate $\mathrm{CO}_{2}$ concentrations, and their uncertainties, in endmember mantle components within the Iceland plume. We find evidence that $\mathrm{CO}_{2}$ concentrations higher than in the depleted mantle are present within the primordial mantle, and lower in recycled mantle (though poorly constrained).

\section{Samples and Methods}

Samples were collected from four fresh primitive eruptions in Iceland (Figure 1) which represent diverse mantle sources, as indicated by their Sr-, Ndand He-isotope ratios. Háleyjabunga and Stapafell are in close proximity on the Reykjanes Peninsula in the Western Rift Zone, but preferentially sample more depleted and enriched mantle components respectively (Thirlwall et al., 2004). Stapafell erupted sub-glacially between 70 and 14 ka (Saemundsson et al., 2010) forming basal pillow basalts, from which samples were taken near $63^{\circ} 54.585 ' \mathrm{~N}$, $22^{\circ} 31.409$ 'W. Háleyjabunga was erupted as a subaerial lava shield at $\sim 13$ ka (Saemundsson et al., 2010), from which olivine-phyric lava flow samples were taken from the Eastern side of the vent near $63^{\circ} 48.978^{\prime} \mathrm{N}, 22^{\circ} 39.099^{\prime} \mathrm{W}$. Berserkjahraun is an eruption younger than $11 \mathrm{ka}$ in the Snæfellsnes flank zone (Hjartarson and Sæmundsson, 2014), and has extreme geochemical enrichment (Peate et al., 2010). Glassy olivine- and plagioclase-phyric scoria was collected from the crater at $64^{\circ} 95.915^{\prime} \mathrm{N}$, $22^{\circ} 89.853^{\prime} \mathrm{W}$. Heilagsdalsfjall is a lava flow erupted in the Northern Volcanic Zone with an age < 11.5 ka (Sæmundsson et al., 2012). Glassy olivinephyric achneliths were collected from the crater at $65.49934^{\circ} \mathrm{N}, 16.70224^{\circ} \mathrm{W}$.

Olivine and clinopyroxene crystals containing melt inclusions were extracted from each sample. The total $\mathrm{CO}_{2}$ content of a melt inclusion is partitioned between the glass and vapour bubble (if present). Following Hartley et al. (2014), crystals were sequentially prepared for micro-Raman analysis of $\mathrm{CO}_{2}$ vapour density in the bubbles, Secondary Ion Mass Spectrometry (SIMS) to determine $\mathrm{CO}_{2}$ and trace element concentrations in the glass, and electron probe microanalysis (EPMA) to determine the major element chemistry of the inclusions and their crystal hosts. Any $\mathrm{CO}_{2}$ detected in the inclusion-hosted bubbles was added back into the glass, assuming the inclusion was a homogeneous melt phase at the time of entrapment. Full information on sample preparation and analytical setup is given in the Supplementary Information. In Appendix A we explain why we do not apply a correction based on predicting the $\mathrm{CO}_{2}$ vapour density in bubbles. As we are primarily interested in trace element ratios, and $\mathrm{CO}_{2}$ concentrations at the time of eruption, we do not apply post-entrapment crystallisation corrections (though we provide sufficient information in Supplementary Tables that this may be performed).

\section{Results}

The four new datasets from Berserkjahraun ,Háleyjabunga, Heilagsdalsfjall, and Stapafell are described in Section. In Section 3.2 we consider our new datasets alongside others from Iceland to assess whether the mantle $\mathrm{CO}_{2} / \mathrm{Ba}$ ratio has survived the melting process. Finally, we discuss the processes most likely to be controlling the $\mathrm{CO}_{2}$-trace element systematics (Section 3.3).

\section{1. $\mathrm{CO}_{2}$ and trace elements}

Melt inclusion $\mathrm{CO}_{2}$ and $\mathrm{Ba}$ concentrations, with and without bubble corrections, are shown for each eruption in Figure 2. All four eruptions show considerable variation in their $\mathrm{CO}_{2} / \mathrm{Ba}$ ratios, but only Háleyjabunga and Stapafell display positive correlations between $\mathrm{CO}_{2}$ and Ba. Only three Háleyjabunga melt inclusions analysed by SIMS contained bubbles in which $\mathrm{CO}_{2}$ vapour was detected (a further three were measured by Raman only, as shown in Supplementary Figure 1d). Though five Stapafell melt inclusion hosted bubbles contained $\mathrm{CO}_{2}$ vapour (Supplementary Figure 1e), only one was in an inclusion analysed by SIMS. No $\mathrm{CO}_{2}$ vapour was detected in any of the bubbles hosted in Heilagsdalsfjall inclusions. A substantial fraction of Berserkjahraun inclusions contained bubbles in which $\mathrm{CO}_{2}$ vapour was detected. In Háleyjabunga, Stapafell and Berserkjahraun, the highest $\mathrm{CO}_{2}$ concentrations are in inclusions where corrections have 


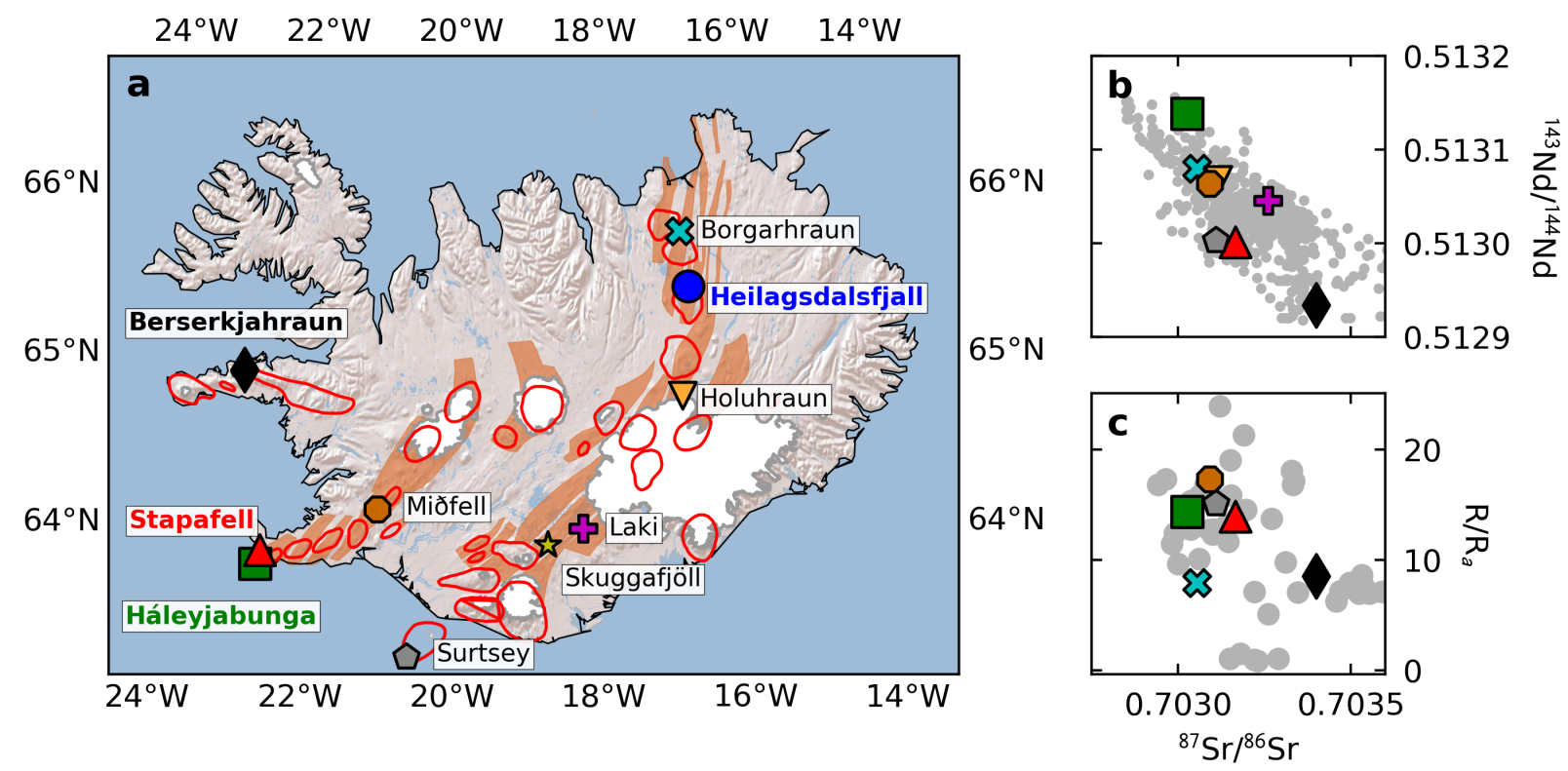

Figure 1: Panel a: Locations of the eruptions studied here (bold text and large symbols), and the locations of other Icelandic eruptions for which $\mathrm{CO}_{2}$ and trace element measurements have been made on melt inclusions. Orange shading shows the active rift zones. Red outlines show active volcanic centres. Panel b: Sr and Nd isotope ratios of whole rocks from the same eruptions. Panel c: ${ }^{3} \mathrm{He} /{ }^{4} \mathrm{He}$ isotope ratio $(R)$ normalised to the atmospheric value $\left(R_{a}\right)$. Grey circles in panels b and c show data compiled for Iceland (sources given in Supplementary Information). Isotope data not available for Skuggafjöll and Heilagsdalsfjall.

been applied. For Háleyjabunga and Stapafell, the corrected inclusions do not have higher $\mathrm{CO}_{2} / \mathrm{Ba}$ than uncorrected inclusions. However, the corrections applied to the Berserkjahraun inclusions are extremely large and consequently significantly increase the $\mathrm{CO}_{2} / \mathrm{Ba}$ ratios recorded by the melt inclusion population. The large magnitude of the corrections arises from high $\mathrm{CO}_{2}$ vapour densities up to $0.75 \mathrm{~g} \mathrm{~cm}^{-3}$. Though this density is above the maximum density of vapour in coexistence with liquid $\mathrm{CO}_{2}$ at room temperature $\left(\sim 0.13 \mathrm{~g} \mathrm{~cm}^{-3}\right)$, any heating by the Raman instrument's laser could move the bubble beyond the $\mathrm{CO}_{2}$ triple point. The bubble volume fraction exerts some control on the corrected $\mathrm{CO}_{2}$ concentration, but little dependence on $\mathrm{CO}_{2}$ vapour density is observed (Supplementary Figure 2). A sub-population of three Háleyjabunga melt inclusions have much higher (bubbleuncorrected) $\mathrm{CO}_{2}$ concentrations than the general population (distinguished on Figures 2 and 3), the origin of this feature is discussed further in Section 3.3 .

Trace element concentrations in the four melt inclusion suites are shown in Figure 3. Melt inclusions from Háleyjabunga (Figure 3a) show ex- treme variability in relative trace element enrichment, Maclennan (2008b) and Neave et al. (2018) argued this variability is most likely mantle derived. The Háleyjabunga matrix has a depleted trace element pattern (Skovgaard et al., 2001). Four Háleyjabunga inclusions have anomalously high Ba and $\mathrm{Nb}$ concentrations relative to the light rare earth elements; since their $\mathrm{CO}_{2}$ concentrations are similar to the main population of inclusions they have not retained high $\mathrm{CO}_{2} / \mathrm{Ba}$ or $\mathrm{CO}_{2} / \mathrm{Nb}$ ratios. The Háleyjabunga inclusion with highest $\mathrm{CO}_{2} / \mathrm{Ba}$ ratio is part of the high- $\mathrm{CO}_{2}$ population, but as we discuss in Section 3.3 this may not reflect a mantle value, and so we treat this inclusion as an anomaly here. Ignoring this anomalous inclusion, the highest $\mathrm{CO}_{2} / \mathrm{Ba}$ ratios $(>200)$ are observed in inclusions with depleted trace element patterns, but are not anomalously depleted among the larger population of Háleyjabunga inclusions.

The Stapafell inclusions with highest $\mathrm{CO}_{2} / \mathrm{Ba}$ (Figure 3b) show trace element patterns with anomalously low $\mathrm{Ba}$ and $\mathrm{Nb}$ concentrations relative to the light and middle rare earth elements. Despite the anomalous trace element patterns of a small number of Stapafell inclusions, $\mathrm{Ba}, \mathrm{Nb}$ and $\mathrm{CO}_{2}$ 

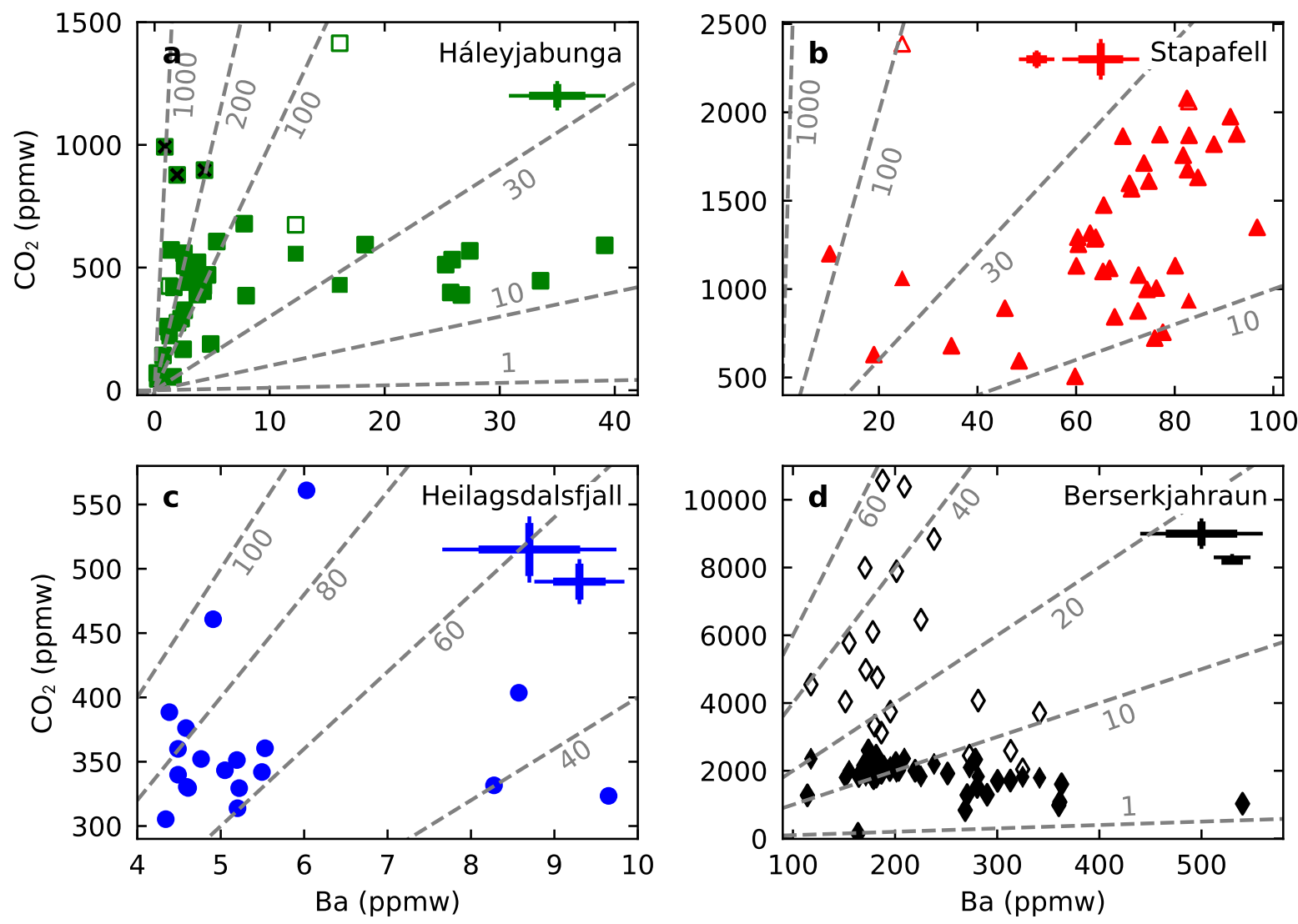

Figure 2: Melt inclusion glass (filled symbols) and reconstructed (open symbols) $\mathrm{CO}_{2}$ concentrations plotted against Ba concentration for each of the four eruptions studied here. The dashed grey lines indicate constant $\mathrm{CO}_{2} / \mathrm{Ba}$ ratio. In panel a (Háleyjabunga), the three inclusions thought to represent a different population, as discussed in the main text, are highlighted with black crosses. Error bars show typical uncertainties for enriched (large error bars), and depleted (small error bars) melt inclusion analyses in each eruption. The bold lines show the estimated 1 s.d. precision, and thin lines show 1 s.d. combined precision and accuracy. The uncertainties for the depleted Háleyjabunga inclusions are smaller than the symbols. 
appear to be unfractionated from each other, discussed further in Section 3.2. The Stapafell melt inclusions show enriched trace element patterns, and our new observations are consistent with the conclusions of Neave et al. (2018) that the variability is not mantle derived, but largely reflects variable crystal fractionation.

The Heilagsdalsfjall melt inclusions (Figure 3c) show little trace element variability, and have a strong depleted mantle signature. Berserkjahraun melt inclusions (Figure 3d) show the most extreme enriched signatures of the four eruptions, and show little mantle-derived variability among the inclusions. The small Sr- and Zr-anomalies seen in many of the inclusions from all four eruptions are likely the result of interaction with plagioclase in the crust (Aigner-Torres et al., 2007).

\subsection{Fractionation of $\mathrm{Ba}, \mathrm{Nb}$ and $\mathrm{CO}_{2}$ during melt- ing}

Primary magmas will only preserve mantle $\mathrm{CO}_{2} / \mathrm{Ba}$ and $\mathrm{CO}_{2} / \mathrm{Nb}$ ratios if $\mathrm{Ba}, \mathrm{Nb}$ and $\mathrm{CO}_{2}$ are not fractionated from each other during mantle melting. Crustal processes are not expected to fractionate $\mathrm{Ba}$ from $\mathrm{Nb}$, but magma degassing will cause $\mathrm{CO}_{2}$ to be fractionated from both. The melt inclusions least affected by degassing can be identified by taking the highest $\mathrm{CO}_{2} / \mathrm{Ba}$ ratios (Matthews et al., 2017).

However, neither this filtering process, nor observations of the distribution of $\mathrm{CO}_{2}$-trace element ratios, can conclusively rule out small degrees of fractionation of $\mathrm{CO}_{2}$ from $\mathrm{Ba}$ and $\mathrm{Nb}$ during melting. Experimental work by Rosenthal et al. (2015) suggests that during mantle melting $\mathrm{CO}_{2}$ should behave marginally more compatibly than $\mathrm{Ba}$, and less compatibly than $\mathrm{Nb}$. Therefore, if $\mathrm{Nb}$ and $\mathrm{Ba}$ have not been fractionated from each other during melting, then it is unlikely that $\mathrm{CO}_{2}$ was fractionated from either. Fractionation of $\mathrm{Ba}$ and $\mathrm{Nb}$ will generate variations in the $\mathrm{Ba} / \mathrm{Nb}$ ratio of melts with $\mathrm{Ba}$ and $\mathrm{Nb}$ concentration. Figure $4 \mathrm{a}$ shows this is not seen in any of the eruptions in this study, or the other Icelandic eruptions in the compilation. The scatter in $\mathrm{Ba} / \mathrm{Nb}$ ratio arises largely from analytical imprecision, but could also reflect small scale source heterogeneity.

Another approach to assessing elemental fractionation during melting is to compare the variability of trace element concentrations. The more incompatibly an element behaves during melting, the greater its variability amongst instantaneous fractional melts of the mantle. If two elements in a dataset have the same mean-normalised variance, the melting process has not fractionated the elements from each other (Rudge et al., 2013). The relative variance of $\mathrm{Ba}$ and $\mathrm{Nb}$ for each Icelandic melt inclusion suite are shown together in Figure $4 \mathrm{~b}$, providing further evidence that $\mathrm{Ba}$ and $\mathrm{Nb}$ have not been fractionated from each other. Elements more compatible than $\mathrm{Nb}$ have been fractionated from each other, as demonstrated by their relative variances (Supplementary Figure 3).

Assuming that the behaviour of $\mathrm{CO}_{2}$ during mantle melting can be modelled as an incompatible element, and that it has a partition coefficient between that of $\mathrm{Ba}$ and $\mathrm{Nb}$ (Rosenthal et al., 2015), the apparent lack of fractionation between $\mathrm{Ba}$ and $\mathrm{Nb}$ would suggest that primary magmatic $\mathrm{CO}_{2} / \mathrm{Ba}$ and $\mathrm{CO}_{2} / \mathrm{Nb}$ ratios will record mantle source ratios.

\subsection{Processes controlling $\mathrm{CO}_{2}$-trace element sys- tematics}

Háleyjabunga and Stapafell both display correlations between $\mathrm{CO}_{2}$ and $\mathrm{Ba}$ concentrations (Figure 2). Additionally, Háleyjabunga shows the increased variance of $\mathrm{CO}_{2}$ concentration with $\mathrm{Ba}$ concentration that is typical of datasets generated by partial degassing and mixing (Matthews et al., 2017). Stapafell exhibits somewhat more complexity, possibly due to a more prolonged history of mixing and fractional crystallisation. Heilagsdalsfjall and Berserkjahraun do not exhibit correlations between $\mathrm{CO}_{2}$ and $\mathrm{Ba}$ concentrations, likely a result of more extensive degassing and mixing.

Three Háleyjabunga melt inclusions (without bubble corrections) form a sub-population with higher $\mathrm{CO}_{2}$ concentrations than the other Háleyjabunga melt inclusions (Figure 2). The higher $\mathrm{CO}_{2}$ concentrations may reflect inclusion entrapment at an earlier stage of magma evolution, where the melts had higher $\mathrm{CO}_{2}$ concentrations due to a greater storage pressure or by less mixing having taken place. The highest $\mathrm{CO}_{2} / \mathrm{Ba}$ ratio in the Háleyjabunga melt inclusions also comes from within this sub-population; if the population is derived simply from being trapped earlier, then this is the value of $\mathrm{CO}_{2} / \mathrm{Ba}$ most likely to reflect the Háleyjabunga mantle source. However, to fully assess this hypothesis by consideration of the sub-population's $\mathrm{CO}_{2}$-trace element systematics requires a much larger sample size. Alternatively, these inclusions may reflect $\mathrm{CO}_{2}$ being added to depleted melts, 


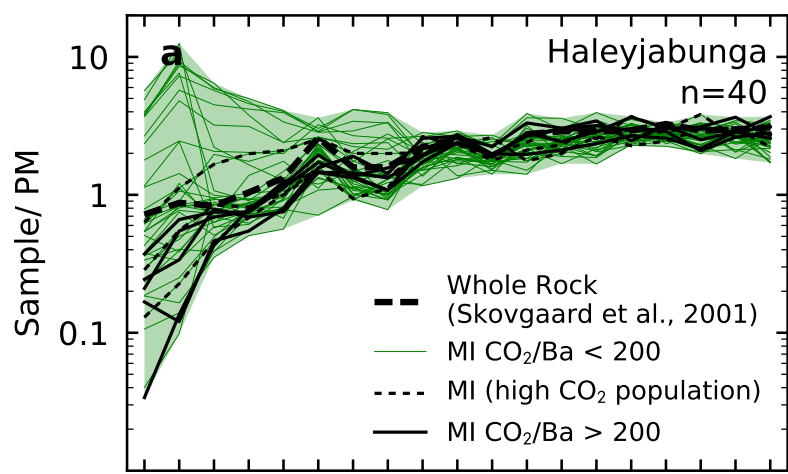

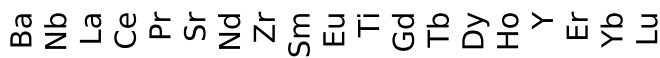

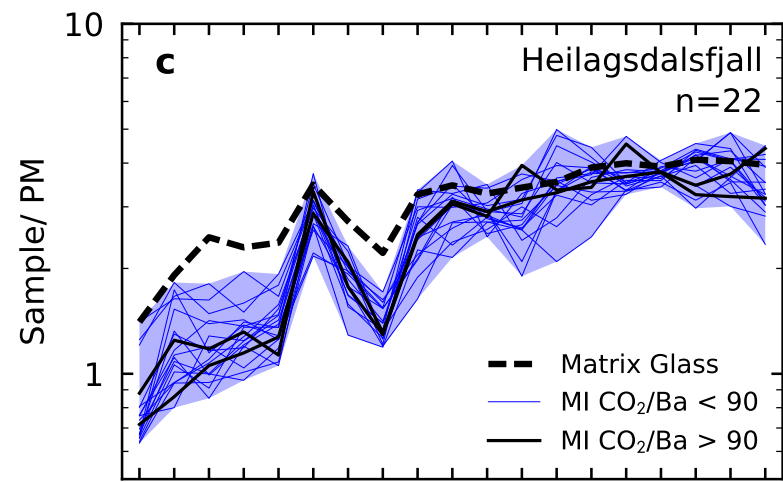

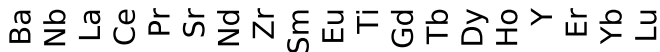

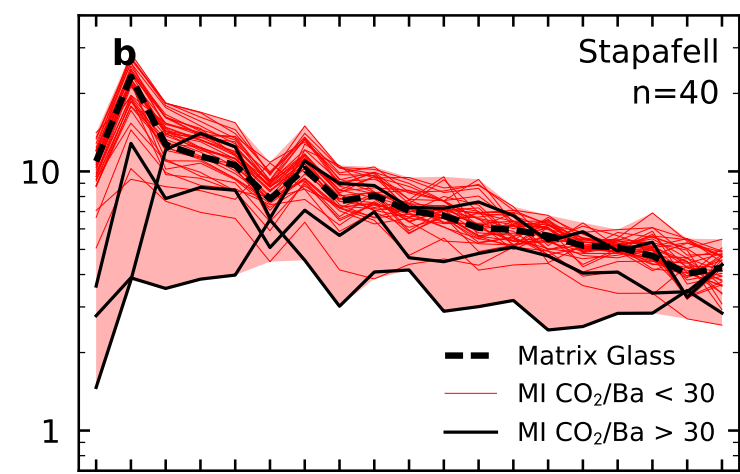

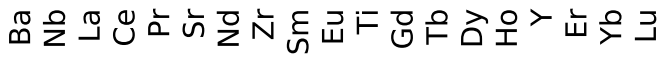

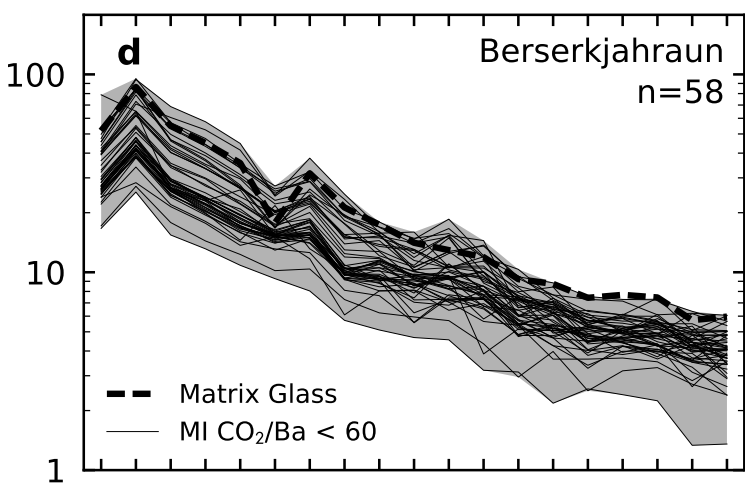

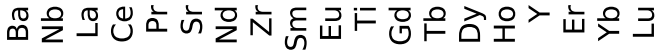

Figure 3: Normalised melt inclusion trace element concentrations. The region between the most extreme melt inclusions of each eruption is shown by shading. Also shown (as thick dashed lines) are the means of matrix glasses analyses for Stapafell, Heilagsdalsfjall and Berserkjahraun, and the whole rock analysis of Háleyjabunga reported by Skovgaard et al. (2001). The melt inclusions preserving the highest $\mathrm{CO}_{2} / \mathrm{Ba}$ ratios are highlighted in black, with the threshold $\mathrm{CO}_{2} / \mathrm{Ba}$ used reported in the legend for each panel. All analyses are normalised to the primitive mantle of Palme and O'Neill (2003). 

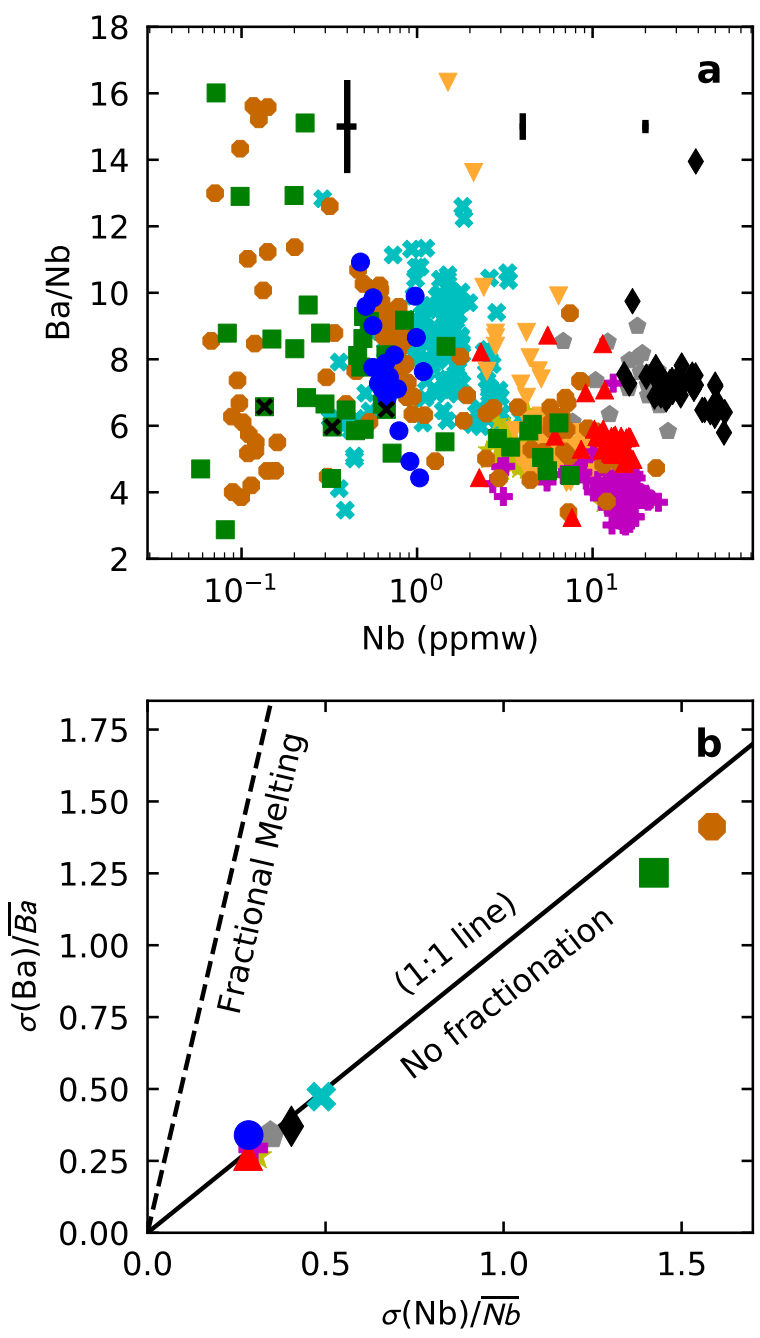

Figure 4: Panel a shows the $\mathrm{Ba} / \mathrm{Nb}$ ratio of the melt inclusions from the eruptions in Figure 1. Three representative error bars are shown, illustrating the 1 s.d. precision on the $\mathrm{Ba} / \mathrm{Nb}$ ratio and $\mathrm{Nb}$ concentrations with varying enrichment, calculated from variably enriched secondary standard analyses. The highest $\mathrm{Ba} / \mathrm{Nb}$ values for Miðfell (Miller et al., 2019) fall off the top of the plot. Panel b compares the standard deviation of $\mathrm{Ba}$ and $\mathrm{Nb}$ in melt inclusions from each eruption, normalised to their mean. The solid line shows the expected relationship if the two elements are not fractionated from each other during melting, the dashed line shows the expected relationship if they are fractionated by perfect fractional melting (Rudge et al., 2013), using the partition coefficients from Workman and Hart (2005). possibly by dissolution of $\mathrm{CO}_{2}$ vapour or by melting in the presence of graphite. Both processes can elevate $\mathrm{CO}_{2}$ concentrations and $\mathrm{CO}_{2} / \mathrm{Ba}$ ratios of depleted melts, and are discussed further in Appendix B. Since we cannot be certain these inclusions represent mantle $\mathrm{CO}_{2} / \mathrm{Ba}$ ratios, we choose to discount them from the following discussion.

\section{Systematics of the Global Melt Inclusion Array}

In Figure 5 we compare our new $\mathrm{CO}_{2}$ and $\mathrm{Ba}$ data from Háleyjabunga, Stapafell, Heilagsdalsfjall and Berserkjahraun, with other Icelandic melt inclusion suites and those from ocean-island and midocean ridge settings. We exclude inclusions from arc volcanoes since their enrichment in $\mathrm{H}_{2} \mathrm{O}$ complicates our understanding of $\mathrm{CO}_{2}$ solubility. In both the Iceland compilation (Figure 5a) and the global compilation (Figure 5b), there is a striking negative correlation between $\mathrm{CO}_{2} / \mathrm{Ba}$ and $\mathrm{Ba}$ concentration. This correlation is bounded above and below by lines of constant $\mathrm{CO}_{2}$ concentration, though bubble-corrected inclusions (unfilled symbols) break through this upper bound. For the most depleted inclusions the low bound corresponds to approximately 100 ppmw $\mathrm{CO}_{2}$, and the high bound to 1000-1400 ppmw $\mathrm{CO}_{2}$. The same systematic is observed in $\mathrm{CO}_{2} / \mathrm{Nb}-\mathrm{Nb}$ space (Supplementary Figure 4).

\subsection{A global array reflecting mantle $\mathrm{CO}_{2}$ hetero- geneity?}

The negative correlation between $\mathrm{CO}_{2} / \mathrm{Ba}$ and Ba concentration could be caused by source heterogeneity. The trace-element enriched mantle reservoirs that contribute disproportionately to the Baenriched melts may not have corresponding $\mathrm{CO}_{2}$ enrichments. However, as the negative correlation has the same position and gradient in both the Icelandic and global datasets, this would imply depleted and enriched mantle components occur with the same distinct $\mathrm{CO}_{2} / \mathrm{Ba}$ and $\mathrm{CO}_{2} / \mathrm{Nb}$ ratios everywhere. Radiogenic isotope constraints demonstrate that there is substantial variation in the chemistry of enriched and depleted components globally, even between highly incompatible elements that are difficult to fractionate during partial melting (e.g. U and Rb) (Stracke et al., 2005). It is therefore perhaps unlikely that these heterogeneous components would be characterised by single $\mathrm{CO}_{2} / \mathrm{Ba}$ and $\mathrm{CO}_{2} / \mathrm{Nb}$ ratios. 
Furthermore, the presence of $\mathrm{CO}_{2}$-rich shrinkage bubbles in many of these inclusions demonstrates that many of the melts must have contained more $\mathrm{CO}_{2}$ in the past, which would have placed them originally above the global array. This is particularly apparent for melt inclusions from Berserkjahraun, Miðfell, Laki and Surtsey (Figure 5a).

\subsection{A global array controlled by degassing?}

A simpler explanation than source heterogeneity is the operation of a process limiting the $\mathrm{CO}_{2}$ concentration within the melt inclusion. The most obvious process is degassing. In this case, the lower limit of $\mathrm{CO}_{2}$ on the array corresponds to $\mathrm{CO}_{2}$ solubility for magma storage in shallow crustal magma chambers. The small number of inclusions with lower $\mathrm{CO}_{2}$ concentrations than this probably owe their undersaturation to degassing during eruption, or mixing with extremely $\mathrm{CO}_{2}$-depleted partial mantle melts (Matthews et al., 2017). The upper bounds on $\mathrm{CO}_{2}$ concentration in depleted melt inclusions of 1000-1400 ppmw correspond to saturation pressures in the range of $1-3 \mathrm{kbar}$, depending on the solubility model chosen (Figure 6, Supplementary Figures 5 and 6). This pressure range coincides with that expected for olivine decrepitation (Wanamaker et al., 1990; Maclennan, 2017), where the crystal undergoes brittle failure when it can no longer support the pressure difference between the inclusion and its surroundings. Experiments by Wanamaker et al. (1990) predict that overpressures of up to $2.2 \mathrm{kbar}$ may be supported. This is very close to the maximum entrapment pressure of the moderately-depleted inclusions when calculated with the $\mathrm{CO}_{2}$ solubility model of Iacono-Marziano et al. (2012), demonstrated in Figure 6.

Figure 5b demonstrates the presence of two different upper limits; one for more depleted eruptions and one for more enriched eruptions. If decrepitation is the process responsible for the upper limit of the array, the limits for both enriched and depleted eruptions ought to correspond to the $\mathrm{CO}_{2}$ solubility at $2.2 \mathrm{kbar}$. However, the dependence of $\mathrm{CO}_{2}$ solubility on melt composition allows significantly different $\mathrm{CO}_{2}$ concentrations to equilibrate at the same pressure in different melts. Melt polymerisation tends to reduce $\mathrm{CO}_{2}$ solubility, whilst the presence of cations with an affinity for forming carbonate complexes increases $\mathrm{CO}_{2}$ solubility (Shishkina et al., 2014).

The enriched inclusions are significantly richer in total-alkalis $\left(\mathrm{Na}_{2} \mathrm{O}+\mathrm{K}_{2} \mathrm{O}\right)$ for similar $\mathrm{SiO}_{2}$ con- tents (Supplementary Figure 7), but this does not translate into significant differences in the $\pi^{*}$ compositional parameter used by Shishkina et al. (2014) in their $\mathrm{CO}_{2}$ solubility model (Supplementary Figure 8). Though the concentration of alkali elements in the enriched inclusions acts to increase the $\mathrm{CO}_{2}$ solubility, their lower $\mathrm{MgO}$ and $\mathrm{CaO}$ concentrations tends to decrease $\mathrm{CO}_{2}$ solubility (Dixon, 1997). As the decrepitation limit should not vary strongly with eruption enrichment, it is likely that the higher $\mathrm{CO}_{2}$ bound for the enriched melts is solubility related, even if not captured by $\pi^{*}$.

A compositional-solubility effect creating the different bounds to the global array is supported by recent experimental work by Allison et al. (2019). By performing new experiments at intermediate pressure and alkaline compositions, Allison et al. (2019) show that existing $\mathrm{CO}_{2}$ solubility models provide inadequate predictions of $\mathrm{CO}_{2}$ solubility in more alkaline melts. Though the least alkaline experimental melt composition used by Allison et al. (2019) is more alkaline than the majority of eruptions from which melt inclusions are displayed in Figure 5, their empirical expression for $\mathrm{CO}_{2}$ solubility likely incorporates other compositional effects of importance for the more enriched eruptions considered here. Figure 6 demonstrates that applying the empirical expression to the more enriched eruptions brings their saturation pressures into line with the depleted eruptions, when the $\mathrm{CO}_{2}$ solubility model by Iacono-Marziano et al. (2012) is applied to the inclusions from depleted eruptions. However, a discrepancy exists if the saturation pressures for depleted eruptions are calculated using the models by Shishkina et al. (2014) and Eguchi and Dasgupta (2018a) (Supplementary Figure 5).

\section{Identifying mantle $\mathrm{CO}_{2}$ heterogeneity}

The gross structure of both the Icelandic and Global melt inclusion arrays shown in Figure 5 is primarily controlled by low-pressure processes: storage in shallow magma chambers and olivine decrepitation (Section 4). However, many eruptions sit almost entirely within the bounds imposed by shallow storage and decrepitation, or have partitioned a significant fraction of their $\mathrm{CO}_{2}$ budget into bubbles and thereby overcoming the decrepitation threshold. Many of these datasets may still preserve the $\mathrm{CO}_{2} / \mathrm{Ba}$ ratios of their melts at the time of entrapment. 


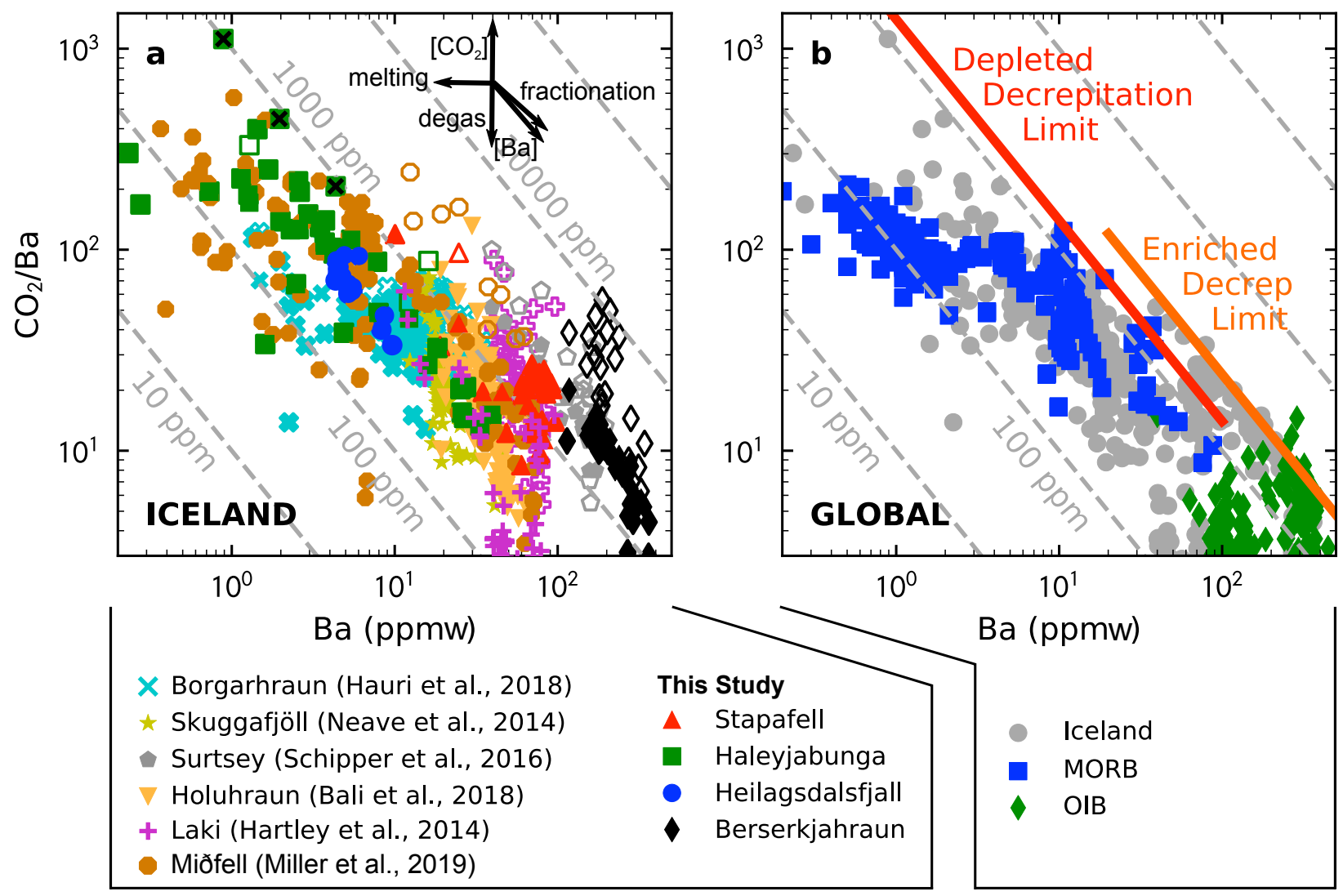

Figure 5: $\mathrm{CO}_{2} / \mathrm{Ba}$ ratios in the melt inclusion glass for the four eruptions studied here, and compiled data from other eruptions in Iceland (panels a and b), from along the mid-ocean ridge system (MORB), and from ocean-islands (OIB) (panel b). Filled symbols show values for $\mathrm{CO}_{2} / \mathrm{Ba}$ derived from $\mathrm{CO}_{2}$ hosted in the glass only, open symbols show the values of $\mathrm{CO}_{2} / \mathrm{Ba}$ where bubbles (measured by Raman) have been added back to the glass. The vectors in panel a show the effects of mantle melting, fractionation during melting, $\mathrm{CO}_{2}$ degassing, $\mathrm{CO}_{2}$ addition, and $\mathrm{Ba}$ addition. Diagonal dashed-grey lines show constant $\mathrm{CO}_{2}$ concentration (10 ppm, $100 \mathrm{ppm}, 1000 \mathrm{ppm}, 1 \mathrm{wt} \%$, and $10 \mathrm{wt} \%$ ). Solid red and orange lines in panel b show the inferred decrepitation limits at $1400 \mathrm{ppmw}$ and $2400 \mathrm{ppmw}$ respectively. The 1 s.d. uncertainty is the size of the markers. Most OIB data falls off the bottom of the figure. Data from Hauri et al. (2018); Hartley et al. (2014); Neave et al. (2014); Schipper et al. (2016); Bali et al. (2018); Le Voyer et al. (2017); Saal et al. (2002); Sides et al. (2014); Wanless and Shaw (2012); Wanless et al. (2014); Cabral et al. (2014); Métrich et al. (2014); Wanless et al. (2015); Tucker et al. (2019). 

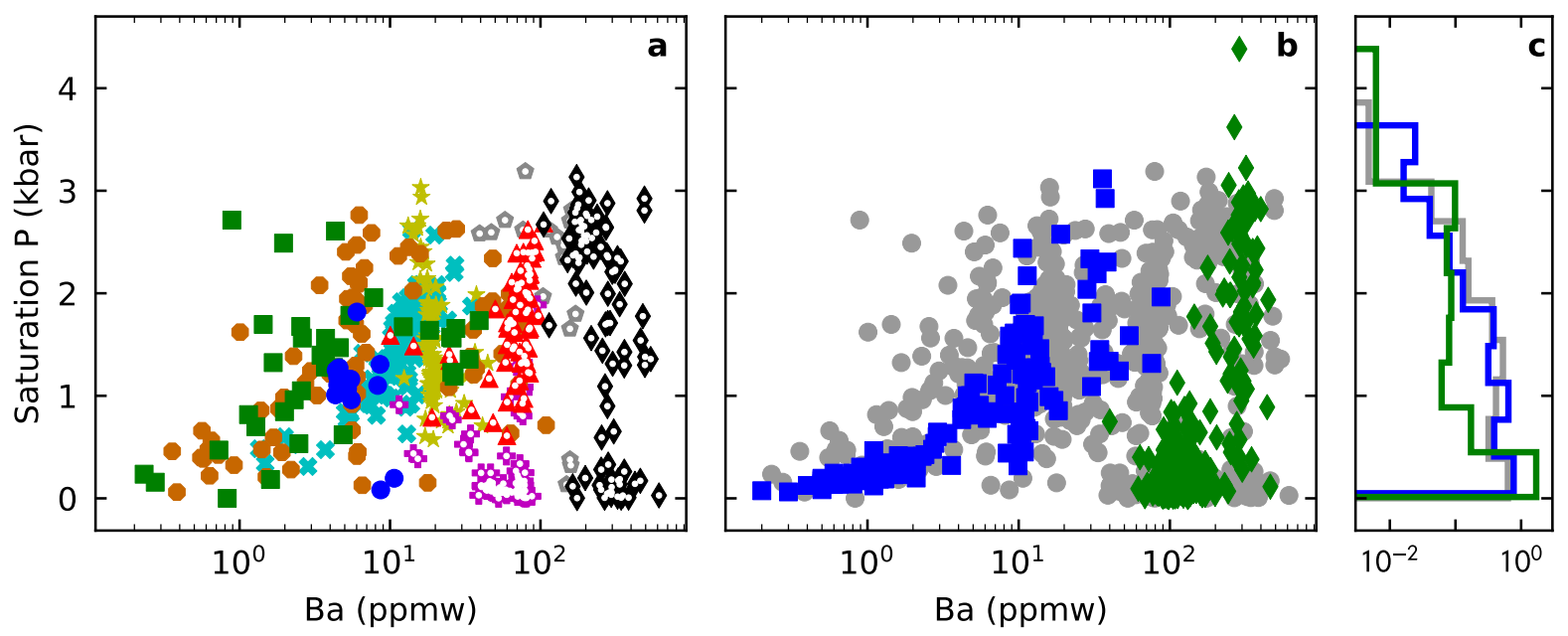

Figure 6: The pressure of $\mathrm{CO}_{2}$ vapour saturation for each melt inclusion in the Iceland compilation (panel a), and the global compilation (panels b and c). Symbols as used in Figure 5. Saturation pressures for melt inclusions from depleted Icelandic eruptions and MORB are calculated using the $\mathrm{CO}_{2}$ solubility model by Iacono-Marziano et al. (2012). Saturation pressures for melt inclusions from enriched Icelandic eruptions (symbols overlaid by white dots in panel a) and OIB are calculated using the power-law fit to experimental data for 'Sunset Crater' by Allison et al. (2019). The effect of $\mathrm{H}_{2} \mathrm{O}$ is neglected in all calculations, as the melts contain sufficiently low $\mathrm{H}_{2} \mathrm{O}$ concentrations that $\mathrm{CO}_{2}$ solubility will be little affected. The calculations do not include bubble-corrections.

However, all the melt inclusion datasets considered here show significant internal variability in the $\mathrm{CO}_{2} / \mathrm{Ba}$ ratios they preserve. Matthews et al. (2017) argued that the diversity of $\mathrm{CO}_{2} / \mathrm{Ba}$ ratios within eruptions indicates that they have experienced partial $\mathrm{CO}_{2}$ loss by degassing, but can regain a positive (albeit scattered) correlation between $\mathrm{CO}_{2}$ and $\mathrm{Ba}$ by magma mixing. We consider the implications of concurrent degassing and mixing for identifying mantle $\mathrm{CO}_{2} / \mathrm{Ba}$ in Section 5.1. Another plausible explanation for diversity in $\mathrm{CO}_{2} / \mathrm{Ba}$ ratios is the mapping of source $\mathrm{CO}_{2} / \mathrm{Ba}$ heterogeneity into its melts. In Section 5.3 we argue such small heterogeneities are likely to be homogenised for individual eruptions during melt generation and transport. Applying the methodology developed in Sections 5.1 and 5.3 to the melt inclusion compilation from Iceland, supplemented with our new data, we identify and place quantitative constraints on $\mathrm{CO}_{2}$ heterogeneity within the Icelandic mantle plume (Section 5.4). We then explore in Section 5.7 whether this approach yields information on the global variability of $\mathrm{CO}_{2}$ in the upper mantle, as sampled by mid-ocean ridge basalts (MORBs).

\subsection{Has concurrent degassing and mixing removed the mantle $\mathrm{CO}_{2} / \mathrm{Ba}$ signal?}

A consequence of concurrent degassing and magma mixing is that the average value of $\mathrm{CO}_{2} / \mathrm{Ba}$ for an eruption is more sensitive to the degassing pressure than to the $\mathrm{CO}_{2} / \mathrm{Ba}$ ratio inherited by the primary melts from their mantle source. Since the degassing, mixing and decrepitation processes all act to lower the $\mathrm{CO}_{2} / \mathrm{Ba}$ ratio recorded by melt inclusions, it follows that the maximum $\mathrm{CO}_{2} / \mathrm{Ba}$ value observed in melt inclusions from a single eruption is the value least affected by $\mathrm{CO}_{2}$ loss and therefore most likely to preserve the mantle $\mathrm{CO}_{2} / \mathrm{Ba}$ ratio.

Any given melt inclusion dataset samples a population of melts with $\mathrm{CO}_{2} / \mathrm{Ba}$ ratios ranging from very low up towards the mantle value. The likelihood of the dataset to sample the true maximum $\mathrm{CO}_{2} / \mathrm{Ba}$ ratio (the mantle value) depends on the relative proportions of these melts, described statistically by a probability distribution. An eruption's $\mathrm{CO}_{2} / \mathrm{Ba}$ distribution may have a long lowprobability tail towards the mantle value, depending on the extent of degassing prior to mixing and the efficiency of mixing. Without knowledge of the distribution of melts entering the crust, and the history of degassing and mixing they subsequently un- 
dergo, it is impossible to constrain the shape of this distribution and therefore assess the likelihood of a given melt inclusion suite preserving the mantle $\mathrm{CO}_{2} / \mathrm{Ba}$ ratio in one or more of the inclusions.

Though we cannot tell whether an individual dataset preserves the mantle $\mathrm{CO}_{2} / \mathrm{Ba}$ ratio when taken in isolation, comparison with a large number of melt inclusions from a diversity of eruptions can provide a context in which to consider the maximum $\mathrm{CO}_{2} / \mathrm{Ba}$ values preserved by an individual eruption. If the maximum $\mathrm{CO}_{2} / \mathrm{Ba}$ ratios of eruptions vary systematically with their mantle sources, and systematic biases from crustal processing can be ruled out, then greater confidence may be placed in the recorded $\mathrm{CO}_{2} / \mathrm{Ba}$ ratios reflecting their mantle source.

\subsection{Are high $\mathrm{CO}_{2} / \mathrm{Ba}$ and $\mathrm{CO}_{2} / \mathrm{Nb}$ ratios analyti- cal artefacts?}

To avoid interpreting analytical artefacts, Rosenthal et al. (2015) and Hirschmann (2018) avoid using the highest $\mathrm{CO}_{2} / \mathrm{Ba}$ values, suggesting these analyses may have incorporated carbon derived from cracks in the sample. Standard practice when collecting melt inclusion datasets is to avoid analyses in the vicinity of cracks, and the ${ }^{12} \mathrm{C}$ count rates would vary erratically in such a situation. In carefully collected datasets such analytical artefacts will be eliminated, and it is more likely that the highest $\mathrm{CO}_{2} / \mathrm{Ba}$ ratios instead reflect sampling of low probability-density tail to the $\mathrm{CO}_{2} / \mathrm{Ba}$ distribution. Furthermore, the inclusions with the highest $\mathrm{CO}_{2} / \mathrm{Ba}$ and $\mathrm{CO}_{2} / \mathrm{Nb}$ have $\mathrm{CO}_{2}$ concentrations that are within the range of the rest of the dataset, and not anomalously high as might be expected if it were an analytical artefact.

In Supplementary Figures 9 and 10 we demonstrate the difference between taking the dataset maximum $\mathrm{CO}_{2} / \mathrm{Ba}$ and $\mathrm{CO}_{2} / \mathrm{Nb}$ ratios, as opposed to the upper limit of the main $\mathrm{CO}_{2} / \mathrm{Ba}$ and $\mathrm{CO}_{2} / \mathrm{Nb}$ data density. The dataset maximum $\mathrm{CO}_{2} / \mathrm{Ba}$ ratios do not coincide with extreme values of $\mathrm{Ba} / \mathrm{Nb}$ (Supplementary Figure 11) or anomalous trace element chemistry (Supplementary Figure 12), suggesting the high values are also not derived from analytical artefacts in trace element concentration measurements. The lack of coincidence between high $\mathrm{CO}_{2} / \mathrm{Ba}$ and extreme $\mathrm{Ba} / \mathrm{Nb}$ provides further evidence that the highest $\mathrm{CO}_{2} / \mathrm{Ba}$ ratios do not arise from fractionation between $\mathrm{Ba}, \mathrm{Nb}$ and $\mathrm{CO}_{2}$ during melting.

\subsection{Preservation of small-scale mantle $\mathrm{CO}_{2}$ het- erogeneity in melts}

In applying the method described above, we are implicitly assuming that the $\mathrm{CO}_{2} / \mathrm{Ba}$ ratio of a single melt inclusion is representative of the heterogeneous mantle that contributes melt to the whole eruption. However, mantle-derived $\mathrm{Pb}$ isotope heterogeneity is present within melt inclusions from single Icelandic eruptions, including single hand-specimens from Háleyjabunga and Stapafell (Maclennan, 2008b). This observation clearly demonstrates that heterogeneity in $\mathrm{Pb}-$ isotope ratios survives the melting and melt transport processes operating beneath Iceland.

However, $\mathrm{CO}_{2}$, $\mathrm{Ba}$ and $\mathrm{Nb}$ are much more incompatible than $\mathrm{Pb}$ and are likely to be almost entirely removed from the solid residue in the first increments of melting. Though channelised mantle flow can transport significant mantle derived chemical heterogeneity in melts, the deepest melts are likely to be well mixed (Spiegelman and Kelemen, 2003; Kelemen et al., 1997), and may subsequently be diluted in varying amounts by higher degree melts. We therefore consider it likely that single eruptions will have mixed out any heterogeneity in $\mathrm{CO}_{2} / \mathrm{Ba}$ and $\mathrm{CO}_{2} / \mathrm{Nb}$ ratios that was present within their mantle source regions. If this is correct, we must look for carbon heterogeneity on an eruption to eruption basis rather than within single eruptions.

By taking the maximum $\mathrm{CO}_{2} / \mathrm{Ba}$ ratio of a melt inclusion dataset we are assuming this is representative of the average mantle sampled by the eruption, as argued above. When we make the comparison between this $\mathrm{CO}_{2} / \mathrm{Ba}$ value, and the bulk-rock radiogenic isotope ratios, we must assume that the isotope ratios are representative of the same mantle average. Since $\mathrm{Pb}, \mathrm{Sr}$, and $\mathrm{Nd}$ are more compatible than $\mathrm{CO}_{2}$ and $\mathrm{Ba}$, melts containing these elements are generated at higher melt fractions, and source heterogeneity can survive melting and transport (Spiegelman and Kelemen, 2003; Kelemen et al., 1997). If the whole rock lava from which the radiogenic isotope measurements are made does not reflect complete mixing of these diverse melts, the $\mathrm{Pb}-, \mathrm{Sr}-$, and $\mathrm{Nd}$-isotope ratios may be decoupled from the maximum $\mathrm{CO}_{2} / \mathrm{Ba}$ and $\mathrm{CO}_{2} / \mathrm{Nb}$ seen in melt inclusions.

Additionally, higher extents of melting are required for a mantle component to contribute to the $\mathrm{Nd}, \mathrm{Sr}$, and $\mathrm{Pb}$ budget of a magma, than for it to contribute to the $\mathrm{CO}_{2}, \mathrm{Ba}$, and $\mathrm{Nb}$ budget. Where 
the extent of melting is controlling the relative contribution of depleted and enriched mantle to the $\mathrm{Pb}-, \mathrm{Nd}-$, and Sr-isotope ratios, rather than source composition, the radiogenic isotopes and the maximum $\mathrm{CO}_{2} / \mathrm{Ba}$ and $\mathrm{CO}_{2} / \mathrm{Nb}$ in melt inclusions may reflect averages of different proportions of the enriched and depleted components in the source.

For the influence of these processes to be properly assessed a much larger number of plausibly undegassed melt inclusion datasets is required. We, therefore, do not consider the possibility of $\mathrm{CO}_{2} / \mathrm{Ba}$ and radiogenic isotope decoupling further. A more robust comparison could be made with radiogenic isotopes of an element at least as incompatible as $\mathrm{Nb}$. One such system is ${ }^{3} \mathrm{He} /{ }^{4} \mathrm{He}$ which we use in complement to $\mathrm{Pb}-, \mathrm{Nd}-$ and $\mathrm{Sr}$-isotopes in the following analysis.

\subsection{Heterogeneity within the Icelandic plume}

Radiogenic isotope observations require multiple enriched and depleted source components within the Icelandic mantle (Thirlwall et al., 2004; Peate et al., 2010; Shorttle et al., 2013). We will use our new data to evaluate whether these mantle components also differ in their $\mathrm{CO}_{2}$ content. The $\mathrm{Pb}-$, $\mathrm{Nd}$-, and Sr-isotope systems are sensitive to ancient melt extraction and recycling events, whilst the ${ }^{3} \mathrm{He} /{ }^{4} \mathrm{He}$ system is diagnostic of primordial (or undegassed) mantle reservoirs.

Though there is a large quantity of melt inclusion data from Iceland, from a number of spatially and temporally restricted eruptions with diverse geochemistry, it is not yet sufficient to fully resolve the $\mathrm{CO}_{2}$ concentrations in the diversity of mantle components beneath Iceland. We therefore proceed on the basis of finding the minimum number of distinct components required to explain the coupled $\mathrm{CO}_{2} / \mathrm{Ba}$ and radiogenic isotope observations, whilst acknowledging the end-members we invert for are some average of the full diversity of heterogeneities present in the Icelandic mantle.

Figures $7 \mathrm{a}$ and $7 \mathrm{~b}$ demonstrate there is no systematic covariation of $\mathrm{CO}_{2} / \mathrm{Ba}$ within ${ }^{206} \mathrm{~Pb} /{ }^{204} \mathrm{~Pb}{ }^{208} \mathrm{~Pb} /{ }^{204} \mathrm{~Pb}$ space, nor ${ }^{87} \mathrm{Sr} /{ }^{86} \mathrm{Sr}-$ ${ }^{143} \mathrm{Nd} /{ }^{144} \mathrm{Nd}$ space. Though not shown here, this is also true of any combination of $\mathrm{Pb}$-isotopes with Sr- and Nd-isotopes. Whilst the lithophile isotope systems excel at separating contributions from enriched and depleted mantle reservoirs, the primordial mantle lies in the middle of lithophile isotope space (Hart et al., 1992). Helium isotopes, in contrast, reveal contributions from primordial man- tle components clearly, as primitive mantle has extremely high ${ }^{3} \mathrm{He} /{ }^{4} \mathrm{He}$ ratios (e.g., Class and Goldstein, 2005).

When ${ }^{3} \mathrm{He} /{ }^{4} \mathrm{He}$ ratios are plotted with ${ }^{143} \mathrm{Nd} /{ }^{144} \mathrm{Nd}$ ratios (Figure 7c) a covariation of $\mathrm{CO}_{2} / \mathrm{Ba}$ with position across the space does emerge: mantle material with high (primordial) ${ }^{3} \mathrm{He} /{ }^{4} \mathrm{He}$ is associated with high magmatic values of $\mathrm{CO}_{2} / \mathrm{Ba}$, whilst melts derived from depleted mantle (with $R / R_{a} \sim 8$ ) have moderate $\mathrm{CO}_{2} / \mathrm{Ba}$ and those from enriched mantle (with $R / R_{a} \leq 8$ ) have low $\mathrm{CO}_{2} / \mathrm{Ba}$. The same trends are observed if $\mathrm{CO}_{2} / \mathrm{Nb}$ is used in place of $\mathrm{CO}_{2} / \mathrm{Ba}$ (Supplementary Figure 13), and a similar co-variation is observed if the upper-limits of the $\mathrm{CO}_{2} / \mathrm{Ba}$ and $\mathrm{CO}_{2} / \mathrm{Nb}$ ratios in the main data population are used in place of the dataset maxima (Supplementary Figures 14 and 15).

The association of high $\mathrm{CO}_{2} / \mathrm{Ba}$ with primordial undegassed mantle material was first made by Miller et al. (2019), based on the elevated $\mathrm{CO}_{2} / \mathrm{Ba}$ ratios seen in the Miðfell eruption in Iceland. By making a comparison to melt inclusions from Borgarhraun (Hauri et al., 2018), Miller et al. (2019) argue that the elevation in $\mathrm{CO}_{2} / \mathrm{Ba}$ in Miðfell is not caused by crustal processing, since both eruptions have similar trace element concentrations. Though it could be argued that Borgarhraun has seen more extensive $\mathrm{CO}_{2}$ loss by magmatic degassing prior to inclusion entrapment, this seems unlikely given the high $(6-8 \mathrm{kbar})$ pressures of crystallisation (Winpenny and Maclennan, 2011; Neave and Putirka, 2017) and the Borgarhraun melt inclusions' distance from the decrepitation threshold (Figure 5a). Our new data from Háleyjabunga lends further support to hypothesis of Miller et al. (2019) that primordial mantle domains are associated with high $\mathrm{CO}_{2} / \mathrm{Ba}$.

However, the same argument cannot be used when making a comparison to the more enriched eruptions, such as Berserkjahraun and Stapafell, as they have significantly higher trace element concentrations in their melt inclusions. If these melts started off with the same or higher $\mathrm{CO}_{2} / \mathrm{Ba}$ ratio than Borgarhraun, the Stapafell and Berserkjahraun melts should have considerably higher $\mathrm{CO}_{2}$ concentrations. Such high $\mathrm{CO}_{2}$ concentrations make these melts more susceptible to degassing and the inclusions more susceptible to $\mathrm{CO}_{2}$ gas loss during decrepitation; crustal processing will therefore tend to introduce a systematic bias towards low $\mathrm{CO}_{2} / \mathrm{Ba}$ ratios in enriched magmas. Regardless of 

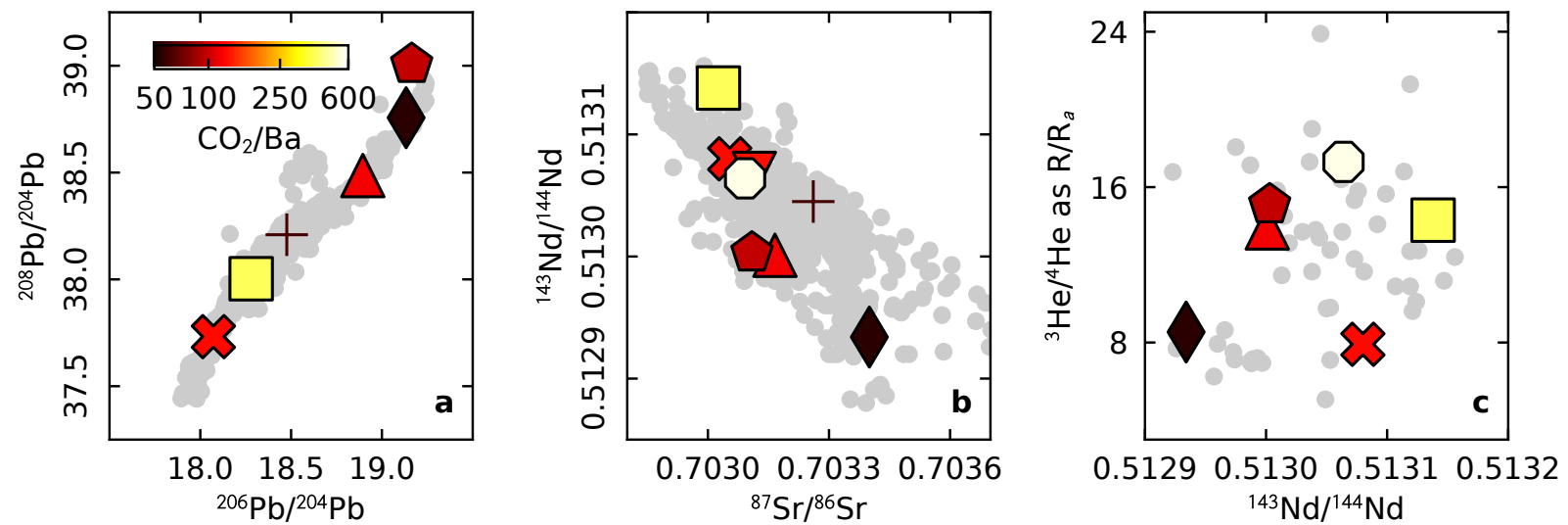

Figure 7: Radiogenic isotope compositions of the whole rocks from eruptions discussed in this text (large symbols), data sources are given in Supplementary Table 3. The symbols used are the same as in Figure 5, but each symbol is colored for the maximum $\mathrm{CO}_{2} / \mathrm{Ba}$ ratio observed in melt inclusions from that eruption, as described in the text. Grey circles show the compilation of Iceland whole-rock isotope analyses, data sources are given in the Supplementary Information.

whether the low $\mathrm{CO}_{2} / \mathrm{Ba}$ in the enriched Berserkjahraun magmas is a result of low $\mathrm{CO}_{2} / \mathrm{Ba}$ in the enriched source or not, we require at least three end-members to deconvolve the primordial mantle signal.

\subsubsection{Inverting for mantle endmember $\mathrm{CO}_{2}$ con- centrations}

Here we consider mixing between three mantle end-members:

1. Depleted mantle (DM)- containing low trace element concentrations with radiogenic $\mathrm{Nd}$ - and He-isotope ratios $\left(R / R_{a} \sim 8\right)$, typical of the MORB-source mantle

2. Enriched mantle (EM)- containing higher trace element concentrations with unradiogenic $\mathrm{Nd}$-isotopes and radiogenic He-isotope ratios $\left(R / R_{a} \leq 8\right)$, representing recycled material

3. Primordial mantle (PM)- containing trace element concentrations and isotope ratios typical of bulk silicate Earth.

The numerical values of their geochemical properties are given in Table 1.

In principle, a mixing surface which closely matches the covariation of $\mathrm{CO}_{2} / \mathrm{Ba}$ across ${ }^{143} \mathrm{Nd} /{ }^{144} \mathrm{Nd}-{ }^{3} \mathrm{He} /{ }^{4} \mathrm{He}$ space can be found. Sohn (2013) developed a mathematical formulation for n-dimensional mixing hyperbolae, when mixing between three end-members this reduces to a surface in three-dimensions. Sohn (2013) demonstrated that the 3-dimensional mixing problem can be reduced to 13 parameters, where Equation 1 is satisfied for values of $\mathrm{CO}_{2} / \mathrm{Ba},{ }^{143} \mathrm{Nd} /{ }^{144} \mathrm{Nd}$ and ${ }^{3} \mathrm{He} /{ }^{4} \mathrm{He}$ lying on the mixing surface:

$$
\operatorname{det} \boldsymbol{M}=0
$$

where

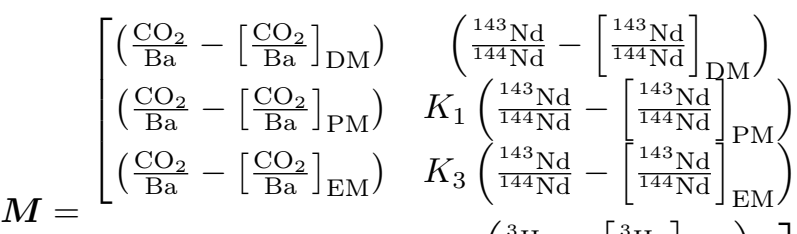

$$
\begin{aligned}
& \begin{array}{c}
\left(\frac{{ }^{3} \mathrm{He}}{{ }^{4} \mathrm{He}}-\left[\frac{{ }^{3} \mathrm{He}}{{ }^{4} \mathrm{He}}\right]_{\mathrm{DM}}\right) \\
K_{2}\left(\frac{{ }^{3} \mathrm{He}}{{ }^{4} \mathrm{He}}-\left[\frac{{ }^{3} \mathrm{He}}{{ }^{4} \mathrm{He}}\right]_{\mathrm{PM}}\right) \\
K_{4}\left({ }^{3} \mathrm{He}-\left[\frac{{ }^{3} \mathrm{He}}{{ }^{4} \mathrm{He}}\right]_{\mathrm{EM}}\right)
\end{array}
\end{aligned}
$$

The subscripts 'DM,' 'PM,' and 'EM' represent endmember values for the depleted, primordial and enriched components respectively. The parameters $\mathrm{K}_{1}, \mathrm{~K}_{2}, \mathrm{~K}_{3}$ and $\mathrm{K}_{4}$ represent ratios of source trace element concentration ratios:

$$
\begin{aligned}
K_{1} & =\frac{[\mathrm{Nd}]_{\mathrm{PM}} /[\mathrm{Ba}]_{\mathrm{PM}}}{[\mathrm{Nd}]_{\mathrm{DM}} /[\mathrm{Ba}]_{\mathrm{DM}}} \\
K_{2} & =\frac{[\mathrm{He}]_{\mathrm{PM}} /[\mathrm{Ba}]_{\mathrm{PM}}}{[\mathrm{He}]_{\mathrm{DM}} /[\mathrm{Ba}]_{\mathrm{DM}}} \\
K_{3} & =\frac{[\mathrm{Nd}]_{\mathrm{EM}} /[\mathrm{Ba}]_{\mathrm{EM}}}{[\mathrm{Nd}]_{\mathrm{DM}} /[\mathrm{Ba}]_{\mathrm{DM}}}
\end{aligned}
$$




$$
K_{4}=\frac{[\mathrm{He}]_{\mathrm{EM}} /[\mathrm{Ba}]_{\mathrm{EM}}}{[\mathrm{He}]_{\mathrm{DM}} /[\mathrm{Ba}]_{\mathrm{DM}}}
$$

i.e., source trace element concentrations will trade off against each other to yield identical surfaces. By combining the concentration ratios into four parameters, the number of free parameters in the inversion is reduced (Sohn, 2013).

In order for our prior assumptions about mantle source chemistry to be applied consistently, we take a Bayesian approach to estimating the $\mathrm{CO}_{2} / \mathrm{Ba}$ ratio and $\mathrm{CO}_{2}$ concentration of the mantle sources. The prior distributions for end-member properties are described in Table 1 and its caption. For the $K_{n}$ parameters log-uniform distributions from $10^{-6}$ to $10^{6}$ were used. We implement the Bayesian calculation using the importance nested sampling Monte-Carlo inversion routine 'Multinest' (Feroz and Hobson, 2008; Feroz et al., 2009, 2013) with the pymultinest python wrapper (Buchner et al., 2014). For simplicity we ignore the uncertainty in the ${ }^{143} \mathrm{Nd} /{ }^{144} \mathrm{Nd}$ and ${ }^{3} \mathrm{He} /{ }^{4} \mathrm{He}$ ratios of the samples, calculating the log-likelihood of each mixing model based only on the misfit between the $\mathrm{CO}_{2} / \mathrm{Ba}$ of the eruption and modelled mixing surface. The total log-likelihood is calculated by summing contributions from each eruption:

$$
\ln (L)=\sum_{1}^{n} \ln \left(L_{n}\left(\mu_{n}, \sigma_{n}, x_{n}\right)\right)
$$

where $\mu_{n}$ is the observed $\mathrm{CO}_{2} / \mathrm{Ba}$ ratio, and $\sigma_{n}$ is its one standard deviation uncertainty. The value of $\mathrm{CO}_{2} / \mathrm{Ba}$ ratio on the modelled mixing surface $\left(x_{n}\right)$ is calculated by numerically solving Equation 1, given the observed ${ }^{143} \mathrm{Nd} /{ }^{144} \mathrm{Nd}$ and ${ }^{3} \mathrm{He} /{ }^{4} \mathrm{He}$ ratios of the samples.

Since the Beserkjahraun, Stapafell, and Surtsey melt inclusions have maximum $\mathrm{CO}_{2} / \mathrm{Ba}$ ratios that fall close to the decrepitation threshold (Figure 5), we treat these observations as minimum bounds on the $\mathrm{CO}_{2} / \mathrm{Ba}$ mixing surface. Models which place the mixing surface at lower values of $\mathrm{CO}_{2} / \mathrm{Ba}$ ratio are penalised by an exponential contribution to the log-likelihood:

$$
\ln \left(L_{n}\right)= \begin{cases}-\exp \left(\left(\mu_{n}-x_{n}\right)^{2}\right), & \text { if } \mu_{n}<x_{n} \\ 0, & \text { otherwise }\end{cases}
$$

Haleyjabunga, Miðfell and Borgarhraun preserve inclusions with high $\mathrm{CO}_{2} / \mathrm{Ba}$ ratios considerably below the decrepitation threshold; therefore, they provide the most direct constraint on the mixing surface. Their contribution to the log-likelihood function reflects their squared normalised distance from the surface:

$$
\ln \left(L_{n}\right)=-\frac{\left(x_{n}-\mu_{n}\right)^{2}}{\sigma_{n}^{2}}
$$

This expression is equivalent to the expression for log-likelihood assuming the constraints follow a normal distribution, with the constant terms removed (Lee, 2012).

Inverting the Sohn (2013) mixing equations provides estimates for only $\mathrm{CO}_{2} / \mathrm{Ba}$ ratios of the three end-members, and not their $\mathrm{CO}_{2}$ concentrations. To estimate $\mathrm{CO}_{2}$ concentration we employ a Monte-Carlo calculation pairing values drawn from the posterior $\mathrm{CO}_{2} / \mathrm{Ba}$ distributions of each endmember with a randomly selected value from a prior distribution of $\mathrm{Ba}$ concentrations of each mantle source (Table 1).

\subsubsection{Inversion results}

The results of the inversion are shown in Figure 8 and Table 2, they represent the first $\mathrm{CO}_{2}$ concentration estimates to be made for different mantle components in one location. Figure 9 shows that our estimate for the depleted mantle $\mathrm{CO}_{2}$ concentration $\left(102_{-14}^{+21} \mathrm{ppmw}\right)$ compares favourably with the concentrations inferred from MORB melt inclusion suites (Rosenthal et al., 2015; Le Voyer et al., 2017), undersaturated glasses (Michael and Graham, 2015) and with estimates derived from $\mathrm{CO}_{2}-\mathrm{He}$ systematics (Marty, 2012; Tucker et al., 2018). Our new estimate for primordial mantle $\left(2.15_{-1.49}^{+0.94} \mathrm{wt} \%\right)$ is much higher than previous estimates of the $\mathrm{CO}_{2}$ content of plume mantle, or bulk mantle as estimated by Marty (2012), whilst our estimate of $\mathrm{CO}_{2}$ concentration in the recycled mantle $\left(68_{-64}^{+1170} \mathrm{ppmw}\right)$ is significantly lower than the plume and bulk mantle estimates. This difference most likely arises from previous estimates averaging high- and low- $\mathrm{CO}_{2}$ mantle reservoirs.

\section{The Depleted Mantle}

When the $\mathrm{DM} \mathrm{CO}_{2} / \mathrm{Ba}$ prior is left open, the inversion routine finds two likelihood maxima; one solution places the high mantle $\mathrm{CO}_{2}$ concentrations into the DM-endmember rather than the PMendmember. Since previous work has shown the depleted mantle has moderately low $\mathrm{CO}_{2}$ concentrations (e.g., Saal et al., 2002; Hirschmann, 2018; 

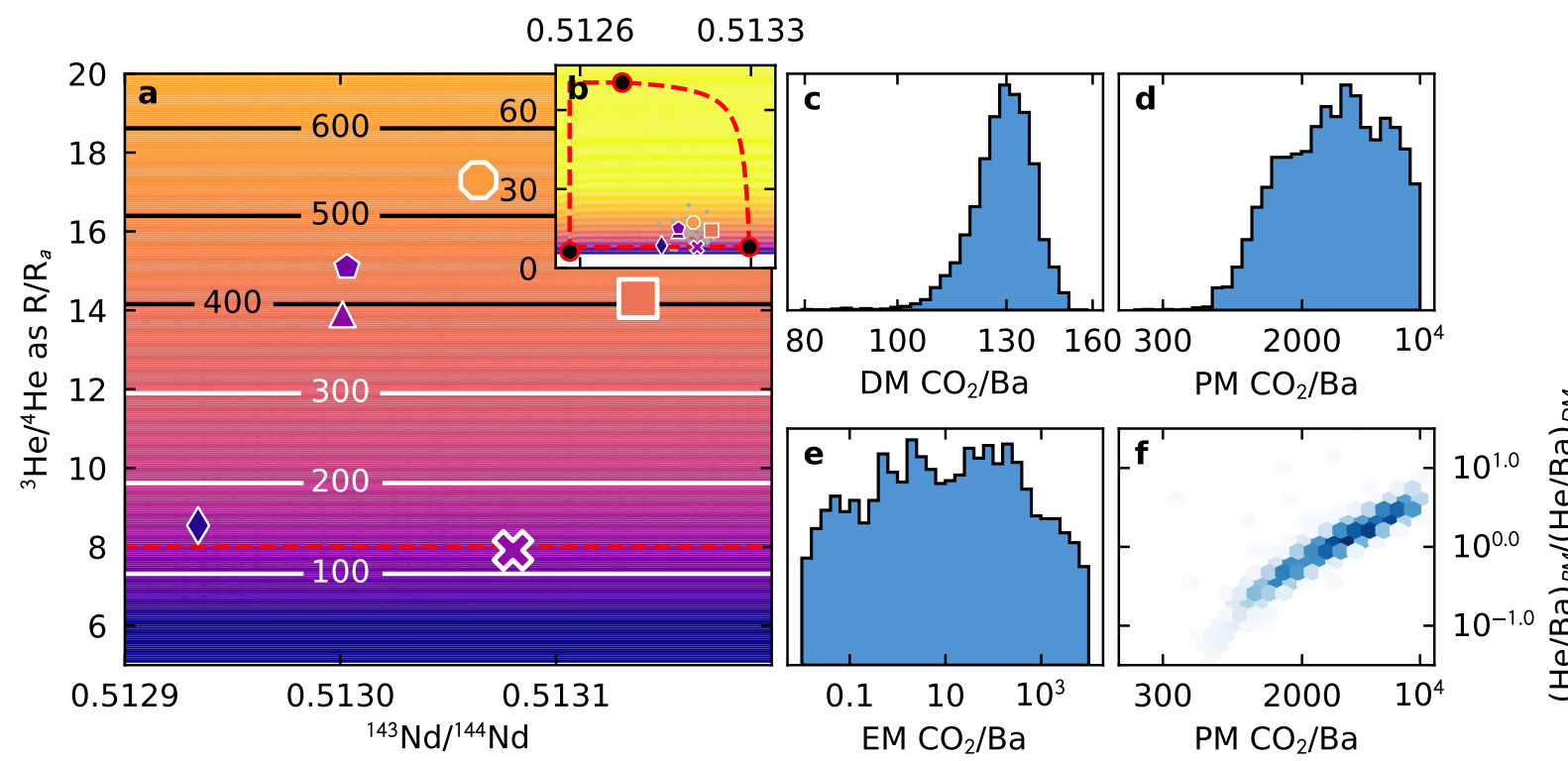

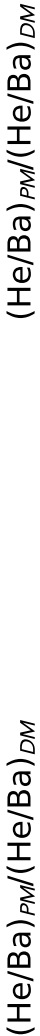
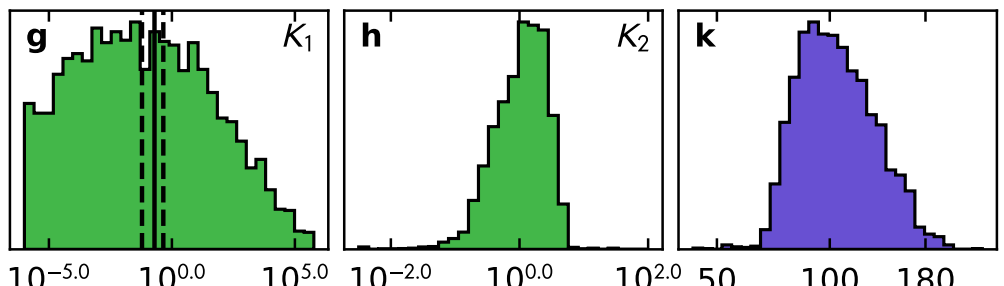

$(\mathrm{Nd} / \mathrm{Ba})_{P M} /(\mathrm{Nd} / \mathrm{Ba})_{D M}(\mathrm{He} / \mathrm{Ba})_{P M} /(\mathrm{He} / \mathrm{Ba})_{D M}$
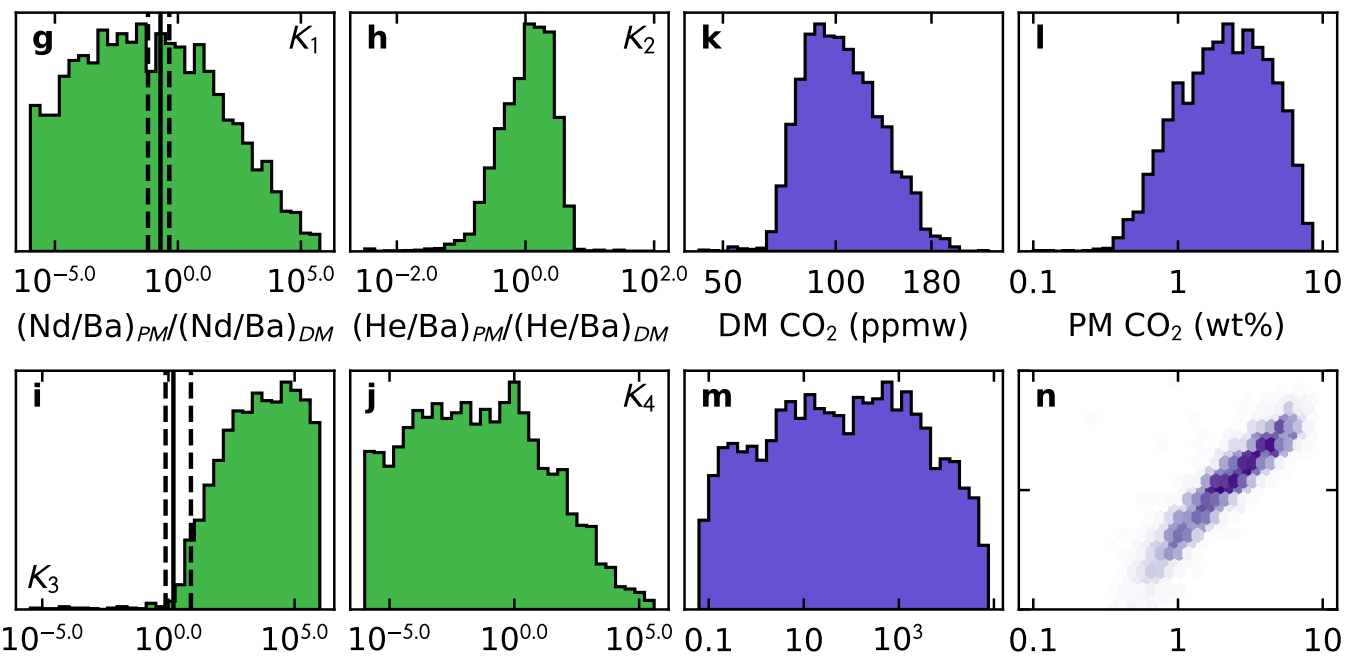

$(\mathrm{Nd} / \mathrm{Ba})_{E M} /(\mathrm{Nd} / \mathrm{Ba})_{D M}(\mathrm{He} / \mathrm{Ba})_{E M} /(\mathrm{He} / \mathrm{Ba})_{D M}$

$\mathrm{EM} \mathrm{CO} 2(\mathrm{ppmw})$

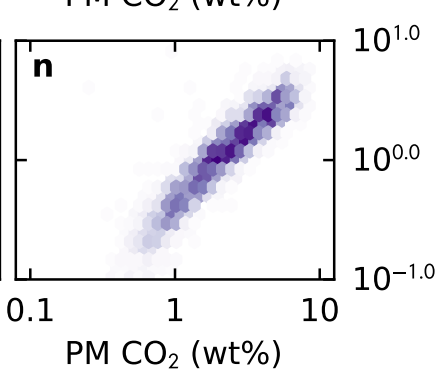

Figure 8: Results of the Bayesian inversion for mantle endmember $\mathrm{CO}_{2}$ concentrations, assuming Haleyjabunga, Miðfell, and Borgarhraun (large symbols in panel a) preserve mantle $\mathrm{CO}_{2} / \mathrm{Ba}$ ratios, whilst Berserkjahraun, Stapafell, and Surtsey (small symbols in panel a) provide only minimum bounds. The colour shading in panels a and b represents the $\mathrm{CO}_{2} / \mathrm{Ba}$ ratio of the fitted surface, with the scale saturating below 50 and above 1200. The eruptions are coloured for their $\mathrm{CO}_{2} / \mathrm{Ba}$ observations on the same scale. The black contours on panel a also show $\mathrm{CO}_{2} / \mathrm{Ba}$ ratio. The dashed red lines on panels a and $\mathrm{b}$ show the extreme mixing boundaries. Panels $\mathrm{c}-\mathrm{e}$ show the posterior distributions for end-member $\mathrm{CO}_{2} / \mathrm{Ba}$. Panel $\mathrm{f}$ shows the trade-off between $\mathrm{PM} \mathrm{CO}_{2} / \mathrm{Ba}$ and $K_{2}$ as a $2 \mathrm{D}$ histogram with shading indicating data density. Panels g-j show the posterior distributions for $K_{1}-K_{4}$. The vertical lines in panels $\mathrm{g}$ and $\mathrm{i}$ show the values for the solid mantle calculated using $\mathrm{Nd}$ and $\mathrm{Ba}$ estimates from Workman and Hart (2005) and Stracke et al. (2003). Panels k-m show the posterior $\mathrm{CO}_{2}$ concentrations calculated from the posterior $\mathrm{CO}_{2} / \mathrm{Ba}$ distributions. Panel n shows the trade-off between mantle $\mathrm{CO}_{2}$ concentration and $K_{2}$. 


\begin{tabular}{lllc}
\hline Parameter & $\mathrm{DM}$ & $\mathrm{EM}$ & $\mathrm{PM}$ \\
\hline $\mathrm{CO}_{2} / \mathrm{Ba}$ & $50-150^{\mathrm{a}}$ & $0.01-1 \times 10^{4}$ & $1-1 \times 10^{4}$ \\
$(\log$-uniform $)$ & See caption $^{\mathrm{a}}$ & Upper limit $\sim 10 \mathrm{wt} \% \mathrm{CO}_{2}$ in mantle \\
${ }^{143} \mathrm{Nd} /{ }^{144} \mathrm{Nd}$ & $0.5132-0.5134$ & $0.5122-0.5129$ & $0.512638-0.51290$ \\
& $\mathrm{Su}(2003)$ & See caption $^{\mathrm{b}}$ & See caption $^{\mathrm{c}}$ \\
$\mathrm{R} / \mathrm{R}_{\mathrm{a}}$ & $8.00 \pm 0.05$ & $5.0-7.4$ & $50-95$ \\
& Kurz and Jenkins (1981) & See caption & See caption $^{\mathrm{e}}$ \\
$\mathrm{Ba}($ ppmw $)$ & $0.58 \pm 0.32$ & $2.55 \pm 0.25$ & $6.9 \pm 1.0$ \\
& Workman and Hart $(2005)$ & Stracke et al. $(2003)^{\mathrm{f}}$ & Palme and O'Neill (2003) \\
\hline
\end{tabular}

Table 1: The priors set on the parameters in the inversions reported in the main text. The sources from which the priors are based are shown in the table. Where ranges are quoted for isotope ratios a uniform (or log-uniform) distribution between those bounds is used, for trace element concentrations it is a log-uniform distribution. Otherwise a normal distribution with the quoted mean and standard deviation are used. ${ }^{a}$ the prior was chosen in order to obtain the solution where DM has moderate $\mathrm{CO}_{2}$ concentrations, as inferred from previous studies. $\mathrm{b}$ The lower bound is lower than the most extreme basalts (e.g. Stracke et al., 2005), and the upper bound is just lower than the lowest Icelandic basalt. ${ }^{c}$ The low Nd-isotope ratio bound for enriched mantle end-member is taken to be lower than the least radiogenic ocean island basalt (Stracke et al., 2005), and the high bound is taken to be lower than the least radiogenic observation from Iceland (Figure 1). ${ }^{d}$ Lower bound is the $R / R_{a}$ inferred for the EM2 mantle component by Jackson et al. (2007), and the upper bound is the ingrown $\mathrm{R} / \mathrm{R}_{\mathrm{a}}$ of the enriched component after $1 \mathrm{Ga} .{ }^{\mathrm{e}}$ Lower bound is the highest $\mathrm{R} / \mathrm{R}_{\mathrm{a}}$ observed in basalts derived from the Iceland plume (Stuart et al., 2003). The upper bound is the $\mathrm{R} / \mathrm{R}_{\mathrm{a}}$ predicted for entirely undegassed BSE-like mantle (Class and Goldstein, 2005). ${ }^{\mathrm{f}}$ Following Shorttle and Maclennan (2011), the trace element concentrations are taken as a third recycled crust (Stracke et al., 2003), and two thirds depleted mantle (Workman and Hart, 2005).

\begin{tabular}{lcc}
\hline Endmember & $\mathrm{CO}_{2} / \mathrm{Ba}$ & $\mathrm{CO}_{2}(\mathrm{ppmw})$ \\
\hline $\mathrm{DM}$ & $130_{-17}^{+14}$ & $102_{-27}^{+53}$ \\
$\mathrm{EM}$ & $10_{-10}^{+3430}$ & $67_{-67}^{+22000}$ \\
$\mathrm{PM}$ & $3190_{-2230}^{+5370}$ & $22000_{-15000}^{+38000}$ \\
\hline
\end{tabular}

Table 2: Summary of the inversion results described in the main text. Median values and the $5 \%$ and $95 \%$ confidence intervals are given for the $\mathrm{CO}_{2} / \mathrm{Ba}, \mathrm{CO}_{2} / \mathrm{Nb}$ and $\mathrm{CO}_{2}$ concentration of each of the three mantle endmembers (DM, EM and $\mathrm{PM})$.

Hauri et al., 2018), and the primordial component has high $\mathrm{CO}_{2}$ concentrations (Miller et al., 2019), we choose the $\mathrm{DM} \mathrm{CO}_{2} / \mathrm{Ba}$ prior such that only the likelihood-maxima corresponding to this low DM $\mathrm{CO}_{2}$ solution is found (Table 1 ).

\section{The Enriched Mantle}

A consequence of treating the most enriched eruptions as minimum bounds in the inversion is the EM endmember becomes poorly constrained, and may have a $\mathrm{CO}_{2} / \mathrm{Ba}$ ratio both lower or far in excess of the depleted mantle. Though the median EM $\mathrm{CO}_{2} / \mathrm{Ba}$ ratio $(\sim 10)$ is significantly lower than for the DM endmember $(\sim 130)$, the posterior EM $\mathrm{CO}_{2} / \mathrm{Ba}$ distribution depends strongly on the lower bound on the $\mathrm{CO}_{2} / \mathrm{Ba}$ prior. The posterior distribution of $K_{3}$ (Figure 8i) is shifted to higher values than that expected from the $\mathrm{Nd} / \mathrm{Ba}$ ratios of the DM and EM endmembers, shown by the verti- cal lines (Workman and Hart, 2005; Stracke et al., 2003). This offset in $K_{3}$ most likely reflects fractionation during melting. The calculated $\mathrm{CO}_{2} / \mathrm{Ba}$ ratio of the DM end-member is comparable to previous estimates for the upper mantle (Rosenthal et al., 2015; Hirschmann, 2018).

\section{The Primordial Mantle}

The calculated $\mathrm{CO}_{2} / \mathrm{Ba}$ ratio of the $\mathrm{PM}$ endmember is extremely high. However, $\mathrm{CO}_{2} / \mathrm{Ba}$ strongly trades-off against $K_{2}$ (the ratio of $\mathrm{He} / \mathrm{Ba}$ ratios of $\mathrm{PM}$ and $\mathrm{DM})$, this reflects the control of the $K$ parameters on the shape of the surface and the distance of the PM end-member from the constraints. No significant trade-off is seen between $\mathrm{PM} \mathrm{CO}_{2} / \mathrm{Ba}$ ratio and the $\mathrm{PM}^{3} \mathrm{He} /{ }^{4} \mathrm{He}$ and ${ }^{143} \mathrm{Nd} /{ }^{144} \mathrm{Nd}$ ratios within the range of their priors.

Two alternative inversions were also performed. One where we do not assume Berserkjahraun, Stapafell and Surtsey are degassed and instead assume they also preserve mantle $\mathrm{CO}_{2} / \mathrm{Ba}$ ratios (Supplementary Figure 16). In the second inversion we take the most extreme values of $\mathrm{CO}_{2} / \mathrm{Ba}$ ratio observed in Haleyjabunga (Section 3.3) as the mantle source value (Supplementary Figure 17). The resulting surfaces are contorted and do not replicate the observations satisfactorily. 


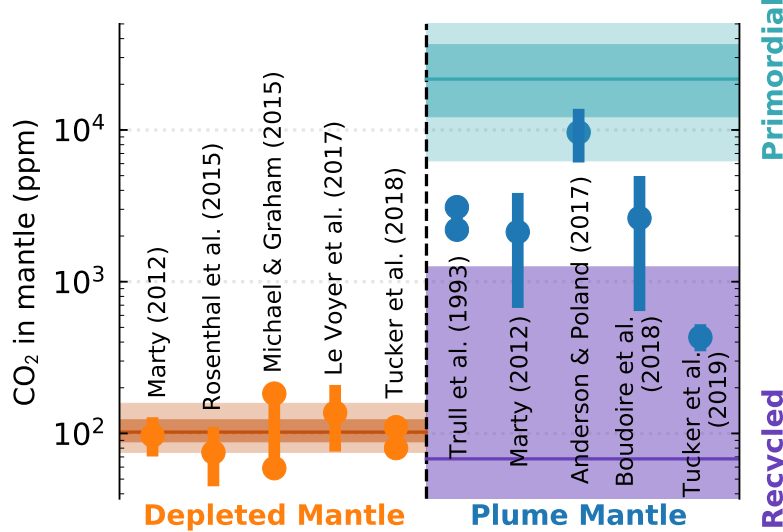

Figure 9: Comparison of our inversion results with previous estimates of the $\mathrm{CO}_{2}$ concentration in depleted mantle and plume mantle. The horizontal bar shows the median value from the posterior distributions of $\mathrm{CO}_{2}$ concentration, the dark shaded region shows the $25 \%$ and $75 \%$ confidence interval, and the light shaded region shows the 5\% and 95\% confidence interval (omitted for EM). The $25 \%$ percentile on the Recycled (EM) result plots below the lower limit of the y-axis. Published estimates from Marty (2012); Rosenthal et al. (2015); Michael and Graham (2015); Le Voyer et al. (2017); Tucker et al. (2018); Trull et al. (1993); Anderson and Poland (2017); Boudoire et al. (2018); Tucker et al. (2019)

\subsection{Difficulties in inferring the recycled mantle $\mathrm{CO}_{2}$ budget}

We have demonstrated that reasonable constraints can be placed on the $\mathrm{CO}_{2}$ budget of depleted and primordial mantle reservoirs. Difficulties remain, however, for identifying the $\mathrm{CO}_{2}$ content of recycled mantle material. The first of these difficulties is made clear by the quantitative analysis above: eruptions which sample predominantly recycled mantle components are also extremely trace element enriched. If the $\mathrm{CO}_{2} / \mathrm{Ba}$ of the recycled mantle material is similar or greater than the depleted mantle, the high trace element concentrations in enriched basalts results in a greater likelihood of $\mathrm{CO}_{2}$ loss due to degassing and decrepitation.

A further difficulty is the possibility for decoupling between the extremely incompatible elements $\mathrm{CO}_{2}, \mathrm{Ba}$ and $\mathrm{Nb}$, and the moderately incompatible elements $\mathrm{Pb}, \mathrm{Nd}$ and $\mathrm{Sr}$. As discussed in Section 5.3, this is unlikely to be an issue for the signal of high $\mathrm{CO}_{2}$ / Ba with high ${ }^{3} \mathrm{He} /{ }^{4} \mathrm{He}$, as $\mathrm{He}$ also behaves extremely incompatibly during mantle melting (Heber et al., 2007).
5.6. Implications of carbon rich mantle reservoirs

The extremely high $\mathrm{CO}_{2} / \mathrm{Ba}$ ratio inferred for the primordial mantle in our inversion (Section 5.4) stems from the observations of high $\mathrm{CO}_{2} / \mathrm{Ba}$ in melt inclusions from two eruptions. One way of rationalising this observation is if the primordial material is extremely depleted in lithophile trace elements, including Ba. Whilst it has been suggested that the high ${ }^{3} \mathrm{He} /{ }^{4} \mathrm{He}$ mantle may be more depleted than bulk silicate Earth (Hart et al., 1992), if the high ${ }^{3} \mathrm{He} /{ }^{4} \mathrm{He}$ mantle were to have similar $\mathrm{CO}_{2}$ concentrations to the depleted mantle it must be at least an order of magnitude more depleted than the depleted mantle to explain the high observed $\mathrm{CO}_{2} / \mathrm{Ba}$ ratio. Though our estimate for the primordial mantle $\mathrm{CO}_{2}$ concentration $\left(2.15_{-1.49}^{+0.94} \mathrm{wt} \%\right)$ is higher than most previous mantle $\mathrm{CO}_{2}$ estimates, it is considerably lower than the carbon content of CI and CM chondrites and similar to the carbon content of the enstatite chondrites, the likely building blocks of the Earth (Wasson and Kallemeyn, 1988).

Our estimate for the primordial mantle $\mathrm{CO}_{2}$ concentration is primarily constrained by the inclusions from Háleyjabunga and Miðfell. These inclusions have slightly lower $\mathrm{CO}_{2}$ concentrations ( $\sim 500 \mathrm{ppmw})$, than inclusions from Borgarhraun ( $\sim 1000$ ppmw), the eruption constraining the depleted mantle $\mathrm{CO}_{2}$ concentration. Magmas produced from a mantle source as rich in carbon as inferred for the primordial component might be expected to also be extremely $\mathrm{CO}_{2}$ rich. However, in our model the Háleyjabunga and Miðfell inclusions have only a small contribution from the primordial component (Figure 8) causing their $\mathrm{CO}_{2}$ concentrations to become substantially diluted, and allowing them to retain their mantle $\mathrm{CO}_{2} / \mathrm{Ba}$ signal. The low trace element concentrations in Háleyjabunga and Miðfell are further evidence of substantial dilution by extremely trace element depleted melts.

This extremely high primordial mantle $\mathrm{CO}_{2}$ budget is considerably greater than can be stored in the peridotite mineral assemblage (Rosenthal et al., 2015), though storage in silicate minerals is implicitly assumed when we treat $\mathrm{CO}_{2}$ as a trace element during melting. For typical mantle oxygen fugacities $\left(f \mathrm{O}_{2}\right)$ carbon is stabilised in a reduced phase (either graphite or diamond) below the melting region (Dasgupta and Hirschmann, 2010). As mantle decompresses, mineral equilibria shift and cause the reduced carbon to be oxidised to carbonate $\left(\mathrm{CO}_{3}^{2-}\right)$. At typical mantle potential temperatures 
this carbonate-bearing assemblage is above the carbonated peridotite solidus, meaning the transition is accompanied by 'redox' melting (Dasgupta and Hirschmann, 2010). Dilution of this melt by higher degree silicate melts is unavoidable; the carbon liberated from the residue by redox melting will have the apparent behaviour of an extremely incompatible element and therefore remain coupled to $\mathrm{Ba}$ and $\mathrm{Nb}$.

If carbon abundances are sufficiently high to influence redox equilibria, or the mantle has anomalously low $f \mathrm{O}_{2}$, reduced carbon may persist into the melting region. In Appendix B we demonstrate that the presence of reduced carbon during melting will result in melts with extremely high $\mathrm{CO}_{2} / \mathrm{Ba}$ ratios, and distinctive $\mathrm{CO}_{2}$-trace element systematics.

\subsection{Global upper mantle $\mathrm{CO}_{2}$ heterogeneity}

Despite the unparalleled quantity of melt inclusion data available for Iceland, we are unable to place robust constraints on the carbon content of recycled mantle components. This limitation is due, in part, to having few eruptions constraining the mixing surface close to the EM-component. An alternative approach for assessing the effect of recycled material on the mantle $\mathrm{CO}_{2}$ budget is to assess global variations in $\mathrm{CO}_{2} / \mathrm{Ba}$ and $\mathrm{CO}_{2} / \mathrm{Nb}$ ratios along the mid-ocean ridge system. The fairly uniform $R / R_{a} \sim 8$ for MORBs means the influence of primordial (high ${ }^{3} \mathrm{He} /{ }^{4} \mathrm{He}$ mantle) is excluded from the dataset. We also include eruptions from Iceland that have $R / R_{a} \sim 8$ (Borgarhraun and Berserkjahraun), in addition to Heilagsdalsfjall as nearby eruptions all have $R / R_{a} \sim 8$ (Harðardóttir et al., 2018), though He-isotope measurements have not been made on Heilagsdalsfjall material. Using the global dataset allows us to populate the DM-EM array with more depleted (but still variably enriched) eruptions, i.e., those which are less susceptible to $\mathrm{CO}_{2}$ loss by magmatic degassing.

Figure 10 shows the compilation (filtered for eruptions with $R / R_{a} \sim 8$ ) of $\mathrm{CO}_{2} / \mathrm{Ba}$ and $\mathrm{CO}_{2} / \mathrm{Nb}$ ratios plotted against ratios used as indices of enrichment: ${ }^{143} \mathrm{Nd} /{ }^{144} \mathrm{Nd}$ (as used in Section 5.4), ${ }^{206} \mathrm{~Pb} /{ }^{204} \mathrm{~Pb}$ and $\mathrm{Ba} / \mathrm{Nb}$. Though not shown here, similar observations can be made with ${ }^{207} \mathrm{~Pb} /{ }^{204} \mathrm{~Pb},{ }^{208} \mathrm{~Pb} /{ }^{204} \mathrm{~Pb}$ and ${ }^{87} \mathrm{Sr} /{ }^{86} \mathrm{Sr}$. Some caution must be exercised with comparing the radiogenic isotopes globally, as source age is convolved with enrichment in the isotope ratio values. As discussed in Section 1, we advocate taking the highest values of $\mathrm{CO}_{2} / \mathrm{Ba}$ and $\mathrm{CO}_{2} / \mathrm{Nb}$ from melt inclusion datasets as the best proxy for the mantle, in preference to the dataset averages often used (Saal et al., 2002; Le Voyer et al., 2017; Hauri et al., 2018). In Figure 10 we highlight the difference between the two approaches for the datasets which preserve correlations between $\mathrm{CO}_{2}$ and the trace elements (filled and unfilled blue circles). We distinguish melt inclusion datasets which do not retain a $\mathrm{CO}_{2}$-trace element correlation (orange circles) since they likely experienced greater extents and a more complex history of $\mathrm{CO}_{2}$ degassing and magma mixing. $\mathrm{CO}_{2}$-undersaturated (ultra-depleted) MORB glasses are shown as grey circles.

Figures 10a, 10b and 10c show there is no systematic variation in $\mathrm{CO}_{2} / \mathrm{Ba}$ with eruption enrichment. Likewise, Figures $10 \mathrm{~d}$ and $10 \mathrm{e}$ show there is no covariation of $\mathrm{CO}_{2} / \mathrm{Nb}$ with radiogenic isotope tracers of eruption enrichment, however a correlation is observed with $\mathrm{Ba} / \mathrm{Nb}$ (Figure 10f). Hirschmann (2018) also described this feature in his compilation of global $\mathrm{CO}_{2} / \mathrm{Ba}$ and $\mathrm{CO}_{2} / \mathrm{Nb}$ ratios, though he found a stronger correlation between $\mathrm{CO}_{2} / \mathrm{Nb}$ and $\mathrm{Ba} / \mathrm{Nb}$ than shown here. This discrepancy arises since Hirschmann (2018) includes datasets associated with plumes (which we do not include as they may have contributions from high ${ }^{3} \mathrm{He} /{ }^{4} \mathrm{He}$ mantle) and presents the undersaturated glass measurements as a set of averages.

The highest $\mathrm{CO}_{2} / \mathrm{Ba}$ ratios observed in datasets with $\mathrm{CO}_{2}$-trace element correlations coincide with the highest $\mathrm{CO}_{2} / \mathrm{Ba}$ ratios seen in the undersaturated glasses, with the exception of the Garrett inclusions where the mean $\mathrm{CO}_{2} / \mathrm{Ba}$ ratio observed in the melt inclusions is closest to the undersaturated glasses. The highest $\mathrm{CO}_{2} / \mathrm{Ba}$ ratio measured in undersaturated glasses from the Siqueiros fracture zones (146 \pm 31 , Michael and Graham, 2015) is intermediate between the mean and highest Siqueiros melt inclusion $\mathrm{CO}_{2} / \mathrm{Ba}$ ratios (though it is within uncertainty of the highest inclusion value). This might suggest that the melts that were preserved as melt inclusions may have experienced some $\mathrm{CO}_{2}$ loss, prior to homogenisation of the trace element and $\mathrm{CO}_{2}$ enriched melts, and before mixing with depleted melts to form a binary mixing array with constant $\mathrm{CO}_{2} / \mathrm{Ba}$ ratio (Matthews et al., 2017, Appendix A). Equally, the undersaturated glasses may reflect a subtly different mantle source. However, the coincidence of the mean $\mathrm{CO}_{2} / \mathrm{Ba}$ ratio of the Garrett melt inclusions with the highest $\mathrm{CO}_{2} / \mathrm{Ba}$ ratios observed in undersaturated glasses lends sup- 

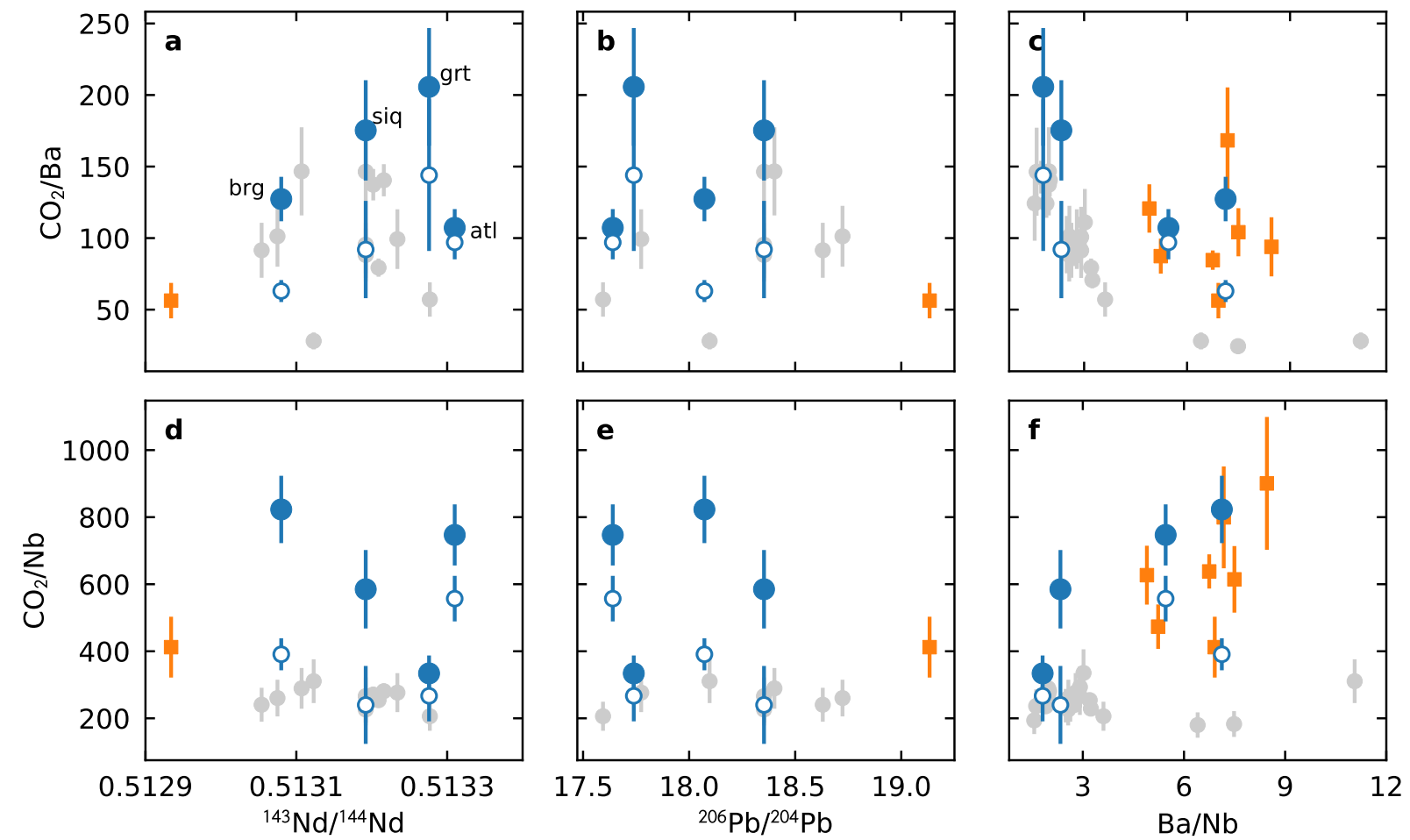

Undersaturated Glass

- MIs with ITE- $\mathrm{CO}_{2}$ correlation (max ratio)

- MIs with ITE- $\mathrm{CO}_{2}$ correlation (average ratio)

- MIs without ITE- $\mathrm{CO}_{2}$ correlation (max ratio)

Figure 10: Compilation of data from the global spreading ridge system, filtered for $R / R_{a} \sim 8$. Melt inclusion datasets are separated into those exhibiting correlations between $\mathrm{CO}_{2}$ and trace elements (blue circles), and those without a correlation (orange squares). For comparison we also show the $\mathrm{CO}_{2} / \mathrm{Ba}$ and $\mathrm{CO}_{2} / \mathrm{Nb}$ ratios that were reported for the datasets exhibiting correlations; these values were derived by taking dataset averages rather than by taking the maximum values as advocated here. Glasses that are undersaturated in $\mathrm{CO}_{2}$ vapour at the pressure of eruption are shown as grey circles. The ${ }^{143} \mathrm{Nd} /{ }^{144} \mathrm{Nd}$, ${ }^{206} \mathrm{~Pb} /{ }^{204} \mathrm{~Pb}$ and $\mathrm{Ba} / \mathrm{Nb}$ ratios for the melt inclusion datasets are taken from published analyses of whole-rock or matrix glass from the same eruptions, for the which the sources are listed in Supplementary Table 3. The melt inclusion datasets with $\mathrm{CO}_{2}$-trace element correlations are labelled in Panel a (brg: Borgarhraun, siq: Siqueiros, grt: Garrett, atl: Equatorial Atlantic). The melt inclusion $\mathrm{CO}_{2} / \mathrm{Ba}$ and $\mathrm{CO}_{2} / \mathrm{Nb}$ ratios are reported by this study, Hauri et al. (2018); Le Voyer et al. (2017); Shimizu et al. (2019); Helo et al. (2011); Wanless and Shaw (2012); Wanless et al. (2014). The undersaturated glass $\mathrm{CO}_{2} / \mathrm{Ba}$ and $\mathrm{CO}_{2} / \mathrm{Nb}$ ratios were reported by Shimizu et al. (2016); Michael and Graham (2015). 
port to the argument of (Shimizu et al., 2019); that the Garrett melt inclusions represent a rare case of the inclusions preserving largely undegassed melts.

Most of the datasets without a $\mathrm{CO}_{2}$-trace element correlation have $\mathrm{CO}_{2} / \mathrm{Ba}$ ratios lower than datasets with a correlation, this could reflect a greater extent of $\mathrm{CO}_{2}$ degassing and mixing seen by the datasets that lack a correlation. The undersaturated glasses have $\mathrm{CO}_{2} / \mathrm{Ba}$ ratios that overlap with the range displayed by the melt inclusion datasets. The lowest $\mathrm{CO}_{2} / \mathrm{Ba}$ ratios $(<50)$ seen in the undersaturated glasses are significantly lower than the $\mathrm{CO}_{2} / \mathrm{Ba}$ ratios seen in melt inclusion datasets at similar $\mathrm{Ba} / \mathrm{Nb}$. Matthews et al. (2017) demonstrated that undersaturation at eruption cannot be taken as evidence that $\mathrm{CO}_{2}$ has not been lost; the undersaturated nature of the glasses may come from mixing of melts undersaturated in $\mathrm{CO}_{2}$ vapour with melts that saturated in $\mathrm{CO}_{2}$ vapour during magma storage. We therefore think it most likely that the undersaturated glasses with lowest $\mathrm{CO}_{2} / \mathrm{Ba}$ lost substantial $\mathrm{CO}_{2}$ vapour during magma storage.

The strength of the correlation between $\mathrm{CO}_{2} / \mathrm{Nb}$ and $\mathrm{Ba} / \mathrm{Nb}$ shown in Figure $10 \mathrm{f}$ arises from the low $\mathrm{CO}_{2} / \mathrm{Nb}$ ratios associated with the samples with low $\mathrm{Ba} / \mathrm{Nb}$. The low $\mathrm{Ba} / \mathrm{Nb}$ samples are from eruptions in fracture zones, including the melt inclusion datasets from the Garrett and Siqueiros fracture zones (Shimizu et al., 2019). Hirschmann (2018) suggests that the correlation may arise from $\mathrm{Nb}$ being fractionated from $\mathrm{Ba}$ and $\mathrm{CO}_{2}$ during mantle melting. Whilst we have shown that $\mathrm{Nb}$ and $\mathrm{Ba}$ are not fractionated from each other during the melting processes that generated the Iceland melt inclusion suites (Section 3.2); the same is not true of Siqueiros. Supplementary Figure 18 demonstrates that the $\mathrm{Ba} / \mathrm{Nb}$ ratio of the Siqueiros inclusions increases with $\mathrm{Ba}$ concentration, and the normalised variances of $\mathrm{Ba}$ and $\mathrm{Nb}$ differ, both observations that suggest $\mathrm{Ba}$ and $\mathrm{Nb}$ have been fractionated from each other during melting. However, $\mathrm{CO}_{2}$ and $\mathrm{Ba}$ have comparable normalised variance, suggesting that they are sufficiently incompatible that they haven't been fractionated from one another and that the $\mathrm{CO}_{2} / \mathrm{Ba}$ ratio should therefore have been largely unaffected by the melting process.

Michael and Graham (2015) suggested that ultradepleted glasses are generated where melt aggregation is incomplete, with a particularly low contribution from the deepest melts. This partial aggregation provides a mechanism for fractionating $\mathrm{Nb}$ from $\mathrm{Ba}$ and $\mathrm{CO}_{2}$ that is likely to only occur in fracture zones, and therefore may explain the origin of the low $\mathrm{CO}_{2} / \mathrm{Nb}$ and $\mathrm{Ba} / \mathrm{Nb}$ population in Figure 10. If fracture-zone eruptions (low $\mathrm{Ba} / \mathrm{Nb}$ ) are discounted from Figure 10, a correlation remains between $\mathrm{Ba} / \mathrm{Nb}$ and $\mathrm{CO}_{2} / \mathrm{Nb}$, though it is weaker. Given that $\mathrm{Ba}$ and $\mathrm{Nb}$ have not been fractionated from each other during melting in the petrogenesis of these non-fracture zone eruptions, this correlation is most likely a source feature and may reflect a decoupling of $\mathrm{Nb}$ and $\mathrm{Ba}$ concentrations during recycling (Hirschmann, 2018).

As discussed in Section 5.3, it is possible that the variation in ${ }^{143} \mathrm{Nd} /{ }^{144} \mathrm{Nd}$ observed between Icelandic eruptions is decoupled from $\mathrm{CO}_{2} / \mathrm{Ba}$ and $\mathrm{CO}_{2} / \mathrm{Nb}$ by melt transport, and so our proxy for source components could be invalid. A more reliable record of the local mantle average $\mathrm{Nd}-$, $\mathrm{Sr}-$ and $\mathrm{Pb}$-isotope ratios is ridge-segment average values (Shorttle, 2015). Supplementary Figure 19 nonetheless demonstrates that $\mathrm{CO}_{2} / \mathrm{Ba}$ and $\mathrm{CO}_{2} / \mathrm{Nb}$ do not co-vary with ridge-segment average $\mathrm{Nd}$ - and $\mathrm{Pb}$-isotope ratios.

\section{Whole mantle $\mathrm{CO}_{2}$ mass balance}

In Section 5.4.2 we demonstrated that reasonable constraints may be placed on the $\mathrm{CO}_{2}$ concentration in a depleted mantle component (DM) and a primordial component (PM) in Iceland, but there is little constraint on the $\mathrm{CO}_{2}$ content in the recycled mantle component (EM). In Section 5.7 we showed that there is little variation in the $\mathrm{CO}_{2} / \mathrm{Ba}$ ratio with degree of enrichment in the upper mantle. If the variable enrichment of the upper mantle is primarily controlled by varying amounts of recycled material (e.g. Chauvel et al., 2008) this might be taken to suggest there is little difference in the $\mathrm{CO}_{2} / \mathrm{Ba}$ ratio of the depleted mantle and recycled mantle.

Marty (2012) estimated a whole mantle averaged $\mathrm{CO}_{2}$ concentration of $2130 \pm 1390$ ppmw. By making the approximation that the whole mantle can be described as a mixture of the three mantle components, DM, EM, and PM, we inverted for using the Iceland data, we can assess the range of EM $\mathrm{CO}_{2}$ concentrations that are consistent with the bulk mantle $\mathrm{CO}_{2}$ estimate made by Marty (2012). Since the relative proportions of the three components are poorly known we allow them each to vary from $0-100 \%$.

Figure 11 shows the $\mathrm{CO}_{2}$ concentration of the EM component required to satisfy this mass balance, as 


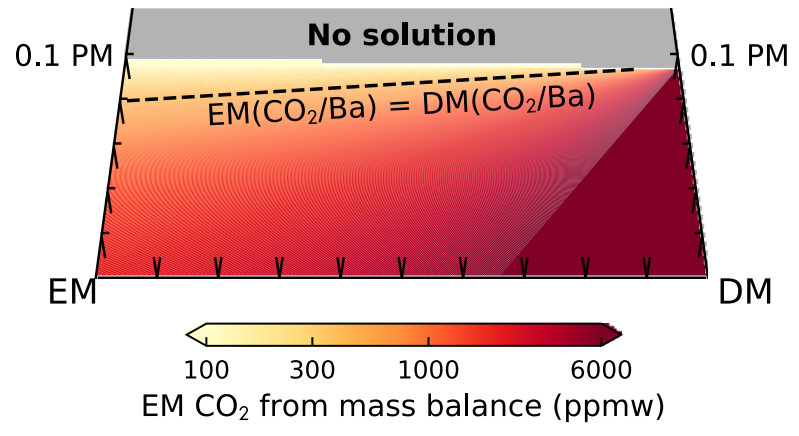

Figure 11: The concentration of $\mathrm{CO}_{2}$ required in the EM component to satisfy mass balance assuming a bulk mantle $\mathrm{CO}_{2}$ concentration of 2130 ppmw (Marty, 2012), plotted here in a ternary diagram of mass fraction. The calculation assumes the DM mantle component has 102 ppmw $\mathrm{CO}_{2}$, and the PM component has $2.2 \mathrm{wt} \%$. The dashed line indicates the locus of solutions where the EM and DM components have the same $\mathrm{CO}_{2} / \mathrm{Ba}$ ratio, assuming a $\mathrm{Ba}$ concentration of $0.563 \mathrm{ppmw}$ in the DM component, and $2.55 \mathrm{ppmw}$ in the EM component (Table 1).

a function of the relative proportions of DM, EM and $\mathrm{PM}$ in the whole mantle. In the calculation the $\mathrm{CO}_{2}$ content of the DM and PM components is taken as the median value of their respective posterior distributions from Section 5.4.2. If the depleted mantle and enriched mantle have the same $\mathrm{CO}_{2} / \mathrm{Ba}$ ratio, $8-10 \%$ of the mantle must be primordial to satisfy this mass balance.

The large low shear velocity provinces (LLSVPs) near the base of the mantle have been suggested to host primordial geochemical signatures (Castillo, 1988), though these account for only $2 \%$ of the mantle's volume (Hernlund and Houser, 2008). Whilst the LLSVPs may be too small to host the required mass of carbon, mass-balance calculations using lithophile elements suggest up to $50 \%$ of the mantle might be primordial (Turcotte et al., 2001). Having $10 \%$ of the mantle bearing primordial high $\mathrm{CO}_{2}$ concentrations is, therefore, perhaps not unreasonable. Further support comes from 2D mantle convection models; Ballmer et al. (2017) demonstrated that $10-15 \%$ of the mantle could remain isolated from convection if those domains are anomalously rich in bridgmanite.

\section{Conclusions}

We have leveraged a large new melt inclusion dataset of trace element and $\mathrm{CO}_{2}$ concentrations in geochemically diverse Icelandic eruptions, alongside existing suites of melt inclusions, to place new constraints on the interplay of source and process on $\mathrm{CO}_{2} / \mathrm{Ba}$ and $\mathrm{CO}_{2} / \mathrm{Nb}$ ratios. The key results are:

1. Though there is a global covariation of $\mathrm{CO}_{2} / \mathrm{Ba}$ with enrichment in melt inclusions, this is a result of olivine decrepitation limiting the $\mathrm{CO}_{2}$ concentration in melt inclusions. Decrepitation may be avoided if a significant fraction of a melt inclusion's $\mathrm{CO}_{2}$ budget is partitioned into a vapour bubble. When the $\mathrm{CO}_{2}$ contained in vapour bubbles is added back into their coexisting glass, substantial heterogeneity in $\mathrm{CO}_{2} / \mathrm{Ba}$ between Icelandic eruptions remains.

2. The maximum $\mathrm{CO}_{2} / \mathrm{Ba}$ and $\mathrm{CO}_{2} / \mathrm{Nb}$ values within Icelandic melt inclusion datasets co-vary with radiogenic isotope proxies for the contributions of depleted, primordial and enriched mantle components to the melts. The highest $\mathrm{CO}_{2} / \mathrm{Ba}$ and $\mathrm{CO}_{2} / \mathrm{Nb}$ are associated with primordial mantle derived melts, and the lowest with enriched mantle derived melts. Whilst it is likely the low $\mathrm{CO}_{2} / \mathrm{Ba}$ and $\mathrm{CO}_{2} / \mathrm{Nb}$ associated with the enriched mantle is due to the greater tendency for enriched melts to be affected by degassing, we argue the elevated $\mathrm{CO}_{2} / \mathrm{Ba}$ and $\mathrm{CO}_{2} / \mathrm{Nb}$ ratios for primordial mantle derived melts relative to depleted mantle is a consequence of elevated $\mathrm{CO}_{2}$ in the solid primordial mantle.

3. Using the observed covariation of $\mathrm{CO}_{2} / \mathrm{Ba}$ and $\mathrm{CO}_{2} / \mathrm{Nb}$ with mantle source we invert for the $\mathrm{CO}_{2}$ concentration in the Icelandic mantle sources, and find concentrations of $102_{-27}^{+53}$ ppmw for the depleted mantle, $2.2_{-1.5}^{+3.8} \mathrm{wt} \%$ for the primordial mantle, and $67_{-67}^{+22000} \mathrm{ppmw}$ for the enriched/recycled mantle. Though the $\mathrm{CO}_{2}$ concentration is likely to be greater in the enriched mantle than the depleted mantle, this could correspond to similar $\mathrm{CO}_{2} / \mathrm{Ba}$ and $\mathrm{CO}_{2} / \mathrm{Nb}$ ratios in both sources.

4. The global mid-ocean ridge $\mathrm{CO}_{2} / \mathrm{Ba}$ and $\mathrm{CO}_{2} / \mathrm{Nb}$ observations show no systematic variation of $\mathrm{CO}_{2} / \mathrm{Ba}$ with enrichment, but do show a variation in $\mathrm{CO}_{2} / \mathrm{Nb}$ with $\mathrm{Ba} / \mathrm{Nb}$ ratio; these observations may suggest similar behaviour of $\mathrm{Ba}$ and $\mathrm{CO}_{2}$ during recycling, but different behaviour of $\mathrm{Nb}$.

5. Our new estimates of mantle source $\mathrm{CO}_{2}$ con- 
centrations are consistent with estimates of the total quantity of $\mathrm{CO}_{2}$ in the mantle.

\section{Acknowledgements}

The authors wish to thank Rob Clarke, Martin Walker and Chris Parish for their assistance with sample preparation, Sébastien Facq for his help with operating the Raman instrument, Iris Buisman for her help with the SEM and EPMA measurements, and Richard Hinton for his help with the SIMS analyses. Helen Williams is thanked for commenting on an early version of the manuscript. Callum Reekie is thanked for helpful discussions. The figures used in this paper were generated with the matplotlib and basemap python packages (Hunter, 2007). Data reduction was performed using the numpy (Oliphant, 2006) and pandas (McKinney, 2010) python packages. The authors would like to thank the Isaac Newton Institute for Mathematical Sciences for its hospitality during the programme 'Melt in the Mantle', which was supported by EPSRC Grant Number EP/K032208/1. SM was supported by a Natural Environment Research Council Studentship NE/L002507/1 and NE/M000427/1. JFR thanks the Leverhulme Trust.

\section{References}

Aigner-Torres, M., Blundy, J., Ulmer, P., Pettke, T., 2007. Laser ablation ICPMS study of trace element partitioning between plagioclase and basaltic melts: an experimental approach. Contributions to Mineralogy and Petrology 153 (6), 647-667.

Allison, C. M., Roggensack, K., Clarke, A. B., 2019. $\mathrm{H}_{2} \mathrm{O}-$ $\mathrm{CO}_{2}$ solubility in alkali-rich mafic magmas: new experiments at mid-crustal pressures. Contributions to Mineralogy and Petrology 174 (7), 58.

Anderson, K. R., Poland, M. P., 2017. Abundant carbon in the mantle beneath Hawai'i. Nature Geoscience 10 (9), 704.

Bali, E., Hartley, M., Halldórsson, S., Gudfinnsson, G., Jakobsson, S., 2018. Melt inclusion constraints on volatile systematics and degassing history of the 2014-2015 Holuhraun eruption, Iceland. Contributions to Mineralogy and Petrology 173 (2), 9.

Ballmer, M. D., Houser, C., Hernlund, J. W., Wentzcovitch, R. M., Hirose, K., 2017. Persistence of strong silicaenriched domains in the Earth's lower mantle. Nature Geoscience 10 (3), 236.

Berry, A. J., Stewart, G. A., O'Neill, H. S. C., Mallmann, G., Mosselmans, J. F. W., 2018. A re-assessment of the oxidation state of iron in MORB glasses. Earth and Planetary Science Letters 483, 114-123.

Boudoire, G., Rizzo, A. L., Di Muro, A., Grassa, F., Liuzzo, M., 2018. Extensive $\mathrm{CO}_{2}$ degassing in the upper mantle beneath oceanic basaltic volcanoes: First insights from Piton de la Fournaise volcano (La Réunion Island). Geochimica et Cosmochimica Acta 235, 376-401.

Buchner, J., Georgakakis, A., Nandra, K., Hsu, L., Rangel, C., Brightman, M., Merloni, A., Salvato, M., Donley, J., Kocevski, D., 2014. X-ray spectral modelling of the AGN obscuring region in the CDFS: Bayesian model selection and catalogue. Astronomy \& Astrophysics 564, A125.

Cabral, R. A., Jackson, M. G., Koga, K. T., Rose-Koga, E. F., Hauri, E. H., Whitehouse, M. J., Price, A. A., Day, J., Shimizu, N., Kelley, K. A., 2014. Volatile cycling of $\mathrm{H}_{2} \mathrm{O}, \mathrm{CO}_{2}, \mathrm{~F}$, and $\mathrm{Cl}$ in the HIMU mantle: A new window provided by melt inclusions from oceanic hot spot lavas at mangaia, cook islands. Geochemistry, Geophysics, Geosystems 15 (11), 4445-4467.

Cartigny, P., Pineau, F., Aubaud, C., Javoy, M., 2008. Towards a consistent mantle carbon flux estimate: Insights from volatile systematics $\left(\mathrm{H}_{2} \mathrm{O} / \mathrm{Ce}, \delta \mathrm{D}, \mathrm{CO}_{2} / \mathrm{Nb}\right)$ in the north atlantic mantle $\left(14^{\circ} \mathrm{N}\right.$ and $\left.34^{\circ} \mathrm{N}\right)$. Earth and Planetary Science Letters 265 (3-4), 672-685.

Castillo, P., 1988. The Dupal anomaly as a trace of the upwelling lower mantle. Nature 336 (6200), 667.

Chauvel, C., Lewin, E., Carpentier, M., Arndt, N. T., Marini, J.-C., 2008. Role of recycled oceanic basalt and sediment in generating the $\mathrm{Hf}-\mathrm{Nd}$ mantle array. Nature geoscience 1 (1), 64 .

Class, C., Goldstein, S. L., 2005. Evolution of helium isotopes in the Earth's mantle. Nature 436 (7054), 1107.

Cottrell, E., Kelley, K. A., 2011. The oxidation state of Fe in MORB glasses and the oxygen fugacity of the upper mantle. Earth and Planetary Science Letters 305 (3), 270282 .

Dasgupta, R., Hirschmann, M. M., 2010. The deep carbon cycle and melting in earth's interior. Earth and Planetary Science Letters 298 (1-2), 1-13.

Dixon, J. E., 1997. Degassing of alkalic basalts. American Mineralogist 82 (3-4), 368-378.

Dixon, J. E., Stolper, E. M., Holloway, J. R., 1995. An experimental study of water and carbon dioxide solubilities in mid-ocean ridge basaltic liquids. Part I: calibration and solubility models. Journal of Petrology 36 (6), 1607-1631.

Duncan, M. S., Dasgupta, R., Tsuno, K., 2017. Experimental determination of $\mathrm{CO}_{2}$ content at graphite saturation along a natural basalt-peridotite melt join: Implications for the fate of carbon in terrestrial magma oceans. Earth and Planetary Science Letters 466, 115-128.

Eguchi, J., Dasgupta, R., 2018a. A $\mathrm{CO}_{2}$ solubility model for silicate melts from fluid saturation to graphite or diamond saturation. Chemical Geology 487, 23-38.

Eguchi, J., Dasgupta, R., 2018b. Redox state of the convective mantle from $\mathrm{CO}_{2}$-trace element systematics of oceanic basalts. Geochemical Perspectives Letters 8.

Feroz, F., Hobson, M., 2008. Multimodal nested sampling: an efficient and robust alternative to Markov Chain Monte Carlo methods for astronomical data analyses. Monthly Notices of the Royal Astronomical Society 384 (2), 449463.

Feroz, F., Hobson, M., Bridges, M., 2009. Multinest: an efficient and robust bayesian inference tool for cosmology and particle physics. Monthly Notices of the Royal Astronomical Society 398 (4), 1601-1614.

Feroz, F., Hobson, M., Cameron, E., Pettitt, A., 2013. Importance nested sampling and the MultiNest algorithm. arXiv preprint arXiv:1306.2144.

Harðardóttir, S., Halldórsson, S. A., Hilton, D. R., 2018. Spatial distribution of helium isotopes in Icelandic 
geothermal fluids and volcanic materials with implications for location, upwelling and evolution of the Icelandic mantle plume. Chemical Geology 480, 12-27.

Hart, S. R., Hauri, E. H., Oschmann, L. A., Whitehead, J. A., 1992. Mantle plumes and entrainment: Isotopic evidence. Science 256 (5056), 517-520.

Hartley, M. E., Maclennan, J., Edmonds, M., Thordarson, T., 2014. Reconstructing the deep $\mathrm{CO}_{2}$ degassing behaviour of large basaltic fissure eruptions. Earth and Planetary Science Letters 393, 120-131.

Hauri, E. H., Maclennan, J., McKenzie, D., Gronvold, K., Oskarsson, N., Shimizu, N., 2018. $\mathrm{CO}_{2}$ content beneath northern Iceland and the variability of mantle carbon. Geology 46 (1), 55-58.

Heber, V. S., Brooker, R. A., Kelley, S. P., Wood, B. J., 2007. Crystal-melt partitioning of noble gases (helium, neon, argon, krypton, and xenon) for olivine and clinopyroxene. Geochimica et Cosmochimica Acta 71 (4), 1041-1061.

Helo, C., Longpré, M.-A., Shimizu, N., Clague, D. A., Stix, J., 2011. Explosive eruptions at mid-ocean ridges driven by $\mathrm{CO}_{2}$-rich magmas. Nature Geoscience 4 (4), 260.

Hernlund, J. W., Houser, C., 2008. On the statistical distribution of seismic velocities in Earth's deep mantle. Earth and Planetary Science Letters 265 (3-4), 423-437.

Hirschmann, M. M., 2018. Comparative deep earth volatile cycles: The case for $\mathrm{C}$ recycling from exosphere/mantle fractionation of major $\left(\mathrm{H}_{2} \mathrm{O}, \mathrm{C}, \mathrm{N}\right)$ volatiles and from $\mathrm{H}_{2} \mathrm{O} / \mathrm{Ce}, \mathrm{CO}_{2} / \mathrm{Ba}$, and $\mathrm{CO}_{2} / \mathrm{Nb}$ exosphere ratios. Earth and Planetary Science Letters.

Hjartarson, Á., Sæmundsson, K., 2014. Geological map of Iceland, bedrock. 1: 600,000. Iceland GeoSurvey, Reykjavík.

Iacono-Marziano, G., Morizet, Y., Le Trong, E., Gaillard, F., 2012. New experimental data and semi-empirical parameterization of $\mathrm{H}_{2} \mathrm{O}-\mathrm{CO}_{2}$ solubility in mafic melts. Geochimica et Cosmochimica Acta 97, 1-23.

Jackson, M. G., Kurz, M. D., Hart, S. R., Workman, R. K., 2007. New Samoan lavas from Ofu island reveal a hemispherically heterogeneous high ${ }^{3}$ he $/{ }^{4}$ he mantle. Earth and Planetary Science Letters 264 (3-4), 360-374.

Jones, M., Wanless, V., Soule, S., Kurz, M., Mittelstaedt, E., Fornari, D., Curtice, J., Klein, F., Le Roux, V., Brodsky, H., et al., 2019. New constraints on mantle carbon from Mid-Atlantic Ridge popping rocks. Earth and Planetary Science Letters 511, 67-75.

Kelemen, P., Hirth, G., Shimizu, N., Spiegelman, M., Dick, H., 1997. A review of melt migration processes in the adiabatically upwelling mantle beneath oceanic spreading ridges. Philosophical Transactions of the Royal Society of London A: Mathematical, Physical and Engineering Sciences 355 (1723), 283-318.

Kelemen, P. B., Manning, C. E., 2015. Reevaluating carbon fluxes in subduction zones, what goes down, mostly comes up. Proceedings of the National Academy of Sciences, 201507889.

Kerrick, D., Connolly, J., 2001. Metamorphic devolatilization of subducted oceanic metabasalts: implications for seismicity, arc magmatism and volatile recycling. Earth and Planetary Science Letters 189 (1-2), 19-29.

Kurz, M., Jenkins, W., 1981. The distribution of helium in oceanic basalt glasses. Earth and Planetary Science Letters 53 (1), 41-54.

Le Voyer, M., Kelley, K., Cottrell, E., Hauri, E., 2017. Heterogeneity in mantle carbon content from $\mathrm{CO}_{2}$ undersaturated basalts. Nature communications 8, 14062.
Lee, P. M., 2012. Bayesian statistics: an introduction. John Wiley \& Sons.

Maclennan, J., 2008a. Concurrent mixing and cooling of melts under iceland. Journal of Petrology 49 (11), 19311953.

Maclennan, J., 2008b. Lead isotope variability in olivinehosted melt inclusions from Iceland. Geochimica et Cosmochimica Acta 72 (16), 4159-4176.

Maclennan, J., 2017. Bubble formation and decrepitation control the $\mathrm{CO}_{2}$ content of olivine-hosted melt inclusions. Geochemistry, Geophysics, Geosystems 18 (2), 597-616.

Marty, B., 2012. The origins and concentrations of water, carbon, nitrogen and noble gases on earth. Earth and Planetary Science Letters 313, 56-66.

Matthews, S., Shorttle, O., Rudge, J. F., Maclennan, J., 2017. Constraining mantle carbon: $\mathrm{CO}_{2}$-trace element systematics in basalts and the roles of magma mixing and degassing. Earth and Planetary Science Letters 480, 1-14.

Métrich, N., Zanon, V., Créon, L., Hildenbrand, A., Moreira, M., Marques, F. O., 2014. Is the 'Azores hotspot' a wetspot? insights from the geochemistry of fluid and melt inclusions in olivine of Pico basalts. Journal of Petrology 55 (2), 377-393.

Michael, P. J., Graham, D. W., 2015. The behavior and concentration of $\mathrm{CO}_{2}$ in the suboceanic mantle: inferences from undegassed ocean ridge and ocean island basalts. Lithos 236, 338-351.

Miller, W. G., Maclennan, J., Shorttle, O., Gaetani, G. A., Le Roux, V., Klein, F., 2019. Estimating the carbon content of the deep mantle with Icelandic melt inclusions. Earth and Planetary Science Letters 523, 115699.

Neave, D. A., Maclennan, J., Edmonds, M., Thordarson, T., 2014. Melt mixing causes negative correlation of trace element enrichment and $\mathrm{CO}_{2}$ content prior to an Icelandic eruption. Earth and Planetary Science Letters 400, 272283.

Neave, D. A., Putirka, K. D., 2017. A new clinopyroxeneliquid barometer, and implications for magma storage pressures under icelandic rift zones. American Mineralogist 102 (4), 777-794.

Neave, D. A., Shorttle, O., Oeser, M., Weyer, S., Kobayashi, K., 2018. Mantle-derived trace element variability in olivines and their melt inclusions. Earth and Planetary Science Letters 483, 90-104.

Palme, H., O'Neill, H. S. C., 2003. Cosmochemical estimates of mantle composition. Treatise on geochemistry 2, 568 .

Peate, D. W., Breddam, K., Baker, J. A., Kurz, M. D., Barker, A. K., Prestvik, T., Grassineau, N., Skovgaard, A. C., 2010. Compositional characteristics and spatial distribution of enriched Icelandic mantle components. Journal of Petrology 51 (7), 1447-1475.

Rosenthal, A., Hauri, E., Hirschmann, M., 2015. Experimental determination of $\mathrm{C}, \mathrm{F}$, and $\mathrm{H}$ partitioning between mantle minerals and carbonated basalt, $\mathrm{CO}_{2} / \mathrm{Ba}$ and $\mathrm{CO}_{2} / \mathrm{Nb}$ systematics of partial melting, and the $\mathrm{CO}_{2}$ contents of basaltic source regions. Earth and Planetary Science Letters 412, 77-87.

Rudge, J. F., Maclennan, J., Stracke, A., 2013. The geochemical consequences of mixing melts from a heterogeneous mantle. Geochimica et Cosmochimica Acta 114, $112-143$.

Saal, A. E., Hauri, E. H., Langmuir, C. H., Perfit, M. R., 2002. Vapour undersaturation in primitive mid-oceanridge basalt and the volatile content of earth's upper mantle. Nature 419 (6906), 451 
Sæmundsson, K., Hjartarson, Á., Kaldal, I., Sigurgeirsson, M., Kristinsson, S., Vikingsson, S., 2012. Geological map of the northern volcanic zone, Iceland. Northern part 1 (100.000).

Saemundsson, K., Jóhannesson, H., Hjartarson, Á., Kristinsson, S. G., Sigurgeirsson, M., 2010. Geological map of southwest Iceland, 1: 100.000. Iceland GeoSurvey.

Schipper, C. I., Le Voyer, M., Moussallam, Y., White, J. D., Thordarson, T., Kimura, J.-I., Chang, Q., 2016. Degassing and magma mixing during the eruption of surtsey volcano (Iceland, 1963-1967): the signatures of a dynamic and discrete rift propagation event. Bulletin of Volcanology $78(4), 33$.

Shimizu, K., Saal, A. E., Hauri, E. H., Perfit, M. R., Hékinian, R., 2019. Evaluating the roles of melt-rock interaction and partial degassing on the $\mathrm{CO}_{2} / \mathrm{Ba}$ ratios of MORB: implications for the $\mathrm{CO}_{2}$ budget in the EarthâÁzs depleted upper mantle. Geochimica et Cosmochimica Acta.

Shimizu, K., Saal, A. E., Myers, C. E., Nagle, A. N., Hauri, E. H., Forsyth, D. W., Kamenetsky, V. S., Niu, Y., 2016. Two-component mantle melting-mixing model for the generation of mid-ocean ridge basalts: implications for the volatile content of the Pacific upper mantle. Geochimica et Cosmochimica Acta 176, 44-80.

Shishkina, T. A., Botcharnikov, R. E., Holtz, F., Almeev, R. R., Jazwa, A. M., Jakubiak, A. A., 2014. Compositional and pressure effects on the solubility of $\mathrm{H}_{2} \mathrm{O}$ and $\mathrm{CO}_{2}$ in mafic melts. Chemical Geology 388, 112-129.

Shorttle, O., 2015. Geochemical variability in MORB controlled by concurrent mixing and crystallisation. Earth and Planetary Science Letters 424, 1-14.

Shorttle, O., Maclennan, J., 2011. Compositional trends of icelandic basalts: Implications for short-length scale lithological heterogeneity in mantle plumes. Geochemistry, Geophysics, Geosystems 12 (11).

Shorttle, O., Maclennan, J., Piotrowski, A. M., 2013. Geochemical provincialism in the Iceland plume. Geochimica et Cosmochimica Acta 122, 363-397.

Shorttle, O., Moussallam, Y., Hartley, M. E., Maclennan, J., Edmonds, M., Murton, B. J., 2015. Fe-XANES analyses of Reykjanes Ridge basalts: Implications for oceanic crust's role in the solid Earth oxygen cycle. Earth and Planetary Science Letters 427, 272-285.

Shorttle, O., Rudge, J. F., Maclennan, J., Rubin, K. H., 2016. A statistical description of concurrent mixing and crystallization during MORB differentiation: implications for trace element enrichment. Journal of Petrology 57 (1112), 2127-2162.

Sides, I., Edmonds, M., Maclennan, J., Swanson, D., Houghton, B., 2014. Eruption style at Kllauea volcano in Hawai'i linked to primary melt composition. Nature Geoscience 7 (6), 464.

Skovgaard, A. C., Storey, M., Baker, J., Blusztajn, J., Hart, S. R., 2001. Osmium-oxygen isotopic evidence for a recycled and strongly depleted component in the Iceland mantle plume. Earth and Planetary Science Letters 194 (1), 259-275.

Sobolev, A., 1996. Melt inclusions in minerals as a source of principle petrological information. Petrology 4 (3), 209220.

Sobolev, A., Shimizu, N., 1993. Ultra-depleted primary melt included in an olivine from the mid-atlantic ridge. Nature 363 (6425), 151.

Sohn, R. A., 2013. A method for inverting ratio-ratio data to estimate end-member compositions in mixing problems. Chemical Geology 352, 63-69.

Spiegelman, M., Kelemen, P. B., 2003. Extreme chemical variability as a consequence of channelized melt transport. Geochemistry, Geophysics, Geosystems 4 (7).

Stolper, E., Holloway, J. R., 1988. Experimental determination of the solubility of carbon dioxide in molten basalt at low pressure. Earth and Planetary Science Letters 87 (4), 397-408.

Stracke, A., Bizimis, M., Salters, V. J., 2003. Recycling oceanic crust: Quantitative constraints. Geochemistry, Geophysics, Geosystems 4 (3).

Stracke, A., Hofmann, A. W., Hart, S. R., 2005. FOZO, HIMU, and the rest of the mantle zoo. Geochemistry, Geophysics, Geosystems 6 (5).

Stuart, F. M., Lass-Evans, S., Fitton, J. G., Ellam, R. M., 2003. High ${ }^{3}$ he $/{ }^{4}$ he ratios in picritic basalts from Baffin island and the role of a mixed reservoir in mantle plumes. Nature 424 (6944), 57.

$\mathrm{Su}$, Y., 2003. Global MORB chemistry compilation at the segment scale. Ph. D. Thesis, Department of Earth and Environmental Sciences, Columbia University.

Thirlwall, M., Gee, M., Taylor, R., Murton, B., 2004. Mantle components in iceland and adjacent ridges investigated using double-spike $\mathrm{Pb}$ isotope ratios. Geochimica et Cosmochimica Acta 68 (2), 361-386.

Trull, T., Nadeau, S., Pineau, F., Polve, M., Javoy, M., 1993. C-He systematics in hotspot xenoliths: Implications for mantle carbon contents and carbon recycling. Earth and Planetary Science Letters 118 (1-4), 43-64.

Tucker, J. M., Hauri, E. H., Pietruszka, A. J., Garcia, M. O., Marske, J. P., Trusdell, F. A., 2019. A high carbon content of the Hawaiian mantle from olivine-hosted melt inclusions. Geochimica et Cosmochimica Acta 254, 156-172.

Tucker, J. M., Mukhopadhyay, S., Gonnermann, H. M., 2018. Reconstructing mantle carbon and noble gas contents from degassed mid-ocean ridge basalts. Earth and Planetary Science Letters 496, 108-119.

Turcotte, D., Paul, D., White, W., 2001. Thorium-uranium systematics require layered mantle convection. Journal of Geophysical Research: Solid Earth 106 (B3), 4265-4276.

Wanamaker, B., Wong, T.-F., Evans, B., 1990. Decrepitation and crack healing of fluid inclusions in San Carlos olivine. Journal of Geophysical Research: Solid Earth 95 (B10), 15623-15641.

Wanless, V., Behn, M., Shaw, A., Plank, T., 2014. Variations in melting dynamics and mantle compositions along the Eastern Volcanic Zone of the Gakkel Ridge: insights from olivine-hosted melt inclusions. Contributions to Mineralogy and Petrology 167 (5), 1005.

Wanless, V. D., Shaw, A. M., 2012. Lower crustal crystallization and melt evolution at mid-ocean ridges. Nature Geoscience 5 (9), 651.

Wanless, V. D., Shaw, A. M., Behn, M. D., Soule, S. A., Escartin, J., Hamelin, C., 2015. Magmatic plumbing at Lucky Strike volcano based on olivine-hosted melt inclusion compositions. Geochemistry, Geophysics, Geosystems 16 (1), 126-147.

Wasson, J. T., Kallemeyn, G. W., 1988. Compositions of chondrites. Philosophical Transactions of the Royal Society of London. Series A, Mathematical and Physical Sciences 325 (1587), 535-544.

Winpenny, B., Maclennan, J., 2011. A partial record of mixing of mantle melts preserved in icelandic phenocrysts. Journal of Petrology 52 (9), 1791-1812. 
Workman, R. K., Hart, S. R., 2005. Major and trace element composition of the depleted MORB mantle (DMM). Earth and Planetary Science Letters 231 (1), 53-72.

\section{Appendix A. Bubble corrections without $\mathrm{CO}_{2}$ vapour density measure- ments}

The bubble corrections applied to the melt inclusions in this study are all derived from observations of the $\mathrm{CO}_{2}$ vapour density in the bubble. An alternative approach that has been used, for example in the Borgarhraun dataset by Hauri et al. (2018), is to calculate the $\mathrm{CO}_{2}$ vapour density that would have been in equilibrium with the melt at the glass transition temperature. However, this assumes that diffusion of $\mathrm{CO}_{2}$ through the inclusion was not kinetically limited. Neave et al. (2014) made comprehensive observations to show that any $\mathrm{CO}_{2}$ present in the bubbles within melt inclusions from the Skuggafjöll eruption must be below detection limit, despite significant $\mathrm{CO}_{2}$ concentrations within the glass. We therefore believe that such corrections must be regarded with great caution.

The variance structure of the Borgarhraun melt inclusions analysed by Hauri et al. (2018) is shown in Figure A.1a. The positive trend between $1 / \sqrt{D}$ and the normalised standard deviation $(\sigma / \mu)$ for elements more incompatible than $\mathrm{Nb}$ is consistent with them being fractionated from each other by fractional melting. The plateau defined by $\mathrm{Nb}$, Th, $\mathrm{U}, \mathrm{Ba}$ and $\mathrm{Rb}$, suggests these elements were not fractionated from each other during fractional melting. Uncorrected $\mathrm{CO}_{2}$ sits below this plateau, indicating the variance in $\mathrm{CO}_{2}$ concentration has been reduced, most likely be partial degassing. When the bubble-corrected $\mathrm{CO}_{2}$ concentrations are used instead (shown by the red $\mathrm{CO}_{2}{ }^{*}$ ) the variance is higher than expected, given the variance of similarly compatible elements. For comparison, Supplementary Figure 3 shows similar plots for the data presented here. Berserkjahraun and Stapafell also have $\mathrm{CO}_{2}$ * with a greater variance than expected. However, Berserkjahraun is most likely to have significant under-corrections for the $\mathrm{CO}_{2}$ it has lost (see main text for discussion) and so this enhanced variance most likely represents scatter from variably incomplete correction. The uncorrected $\mathrm{CO}_{2}$ concentrations from Stapafell also have a higher than expected variance, this is most likely to be generated by the melt inclusions preserving two stages of partial degassing and mixing. Borgarhraun has much simpler $\mathrm{CO}_{2}$-trace element systematics, suggesting a single stage degassing and mixing process. This is supported by the correlation coefficients between $1 / \mathrm{El}$ and $\mathrm{CO}_{2} / \mathrm{El}$ (where $\mathrm{El}$ is the concentration of a trace element) shown in Figure A.1b. If $\mathrm{CO}_{2}$ were behaving identically to a trace element, and had not undergone partial degassing and mixing, the correlation coefficient should rapidly decrease at the partition coefficient for $\mathrm{CO}_{2}$, shown by the vertical dashed line (Matthews et al., 2017). The calculated correction should not give an incomplete correction, and so it is most likely that the elevated variance arises from over-correcting the $\mathrm{CO}_{2}$ concentrations. We therefore omit these corrected values from the analysis presented here.

\section{Appendix B. Graphite Saturated Melting}

The calculations of melt $\mathrm{CO}_{2}$ concentrations in the main text are valid only if carbon is present only as a trace element or as carbonate in the solid mantle. The stability of carbonate over graphite is controlled by the oxygen fugacity $\left(\mathrm{fO}_{2}\right)$ of the mantle (e.g. Dasgupta and Hirschmann, 2010). Eguchi and Dasgupta (2018b) modelled the $\mathrm{CO}_{2} / \mathrm{Ba}$ ratios of basalts with contributions from a graphitesaturated mantle source. They concluded that such models provide a poor fit to natural MORB and OIB, thereby inferring that graphite-saturated melts do not generally contribute to basaltic volcanism. By incorporating graphite saturation into the model used by Matthews et al. (2017) we extend the work of Eguchi and Dasgupta (2018b) by assessing how the signal of graphite-saturated melts might be modulated by the mixing and degassing processes.

The $\mathrm{CO}_{2}$ content of the melt at graphite saturation was calculated as a function of melt composition and $\mathrm{fO}_{2}$ using the formulation of Duncan et al. (2017). Once graphite is exhausted, we assume $\mathrm{CO}_{2}$ is entirely depleted from the solid residue. To maintain consistency with other trace elements, which we model as melting continuously, we allow for $\mathrm{CO}_{2}$ to remain within the residual porosity with a growing degree of dilution and assuming perfectly incompatible behaviour.

For a single melting increment of $d F_{n}$ with a residual porosity of $\phi$ :

$$
C_{n}=\frac{\phi-d F_{n}}{\phi} C_{n-1}
$$



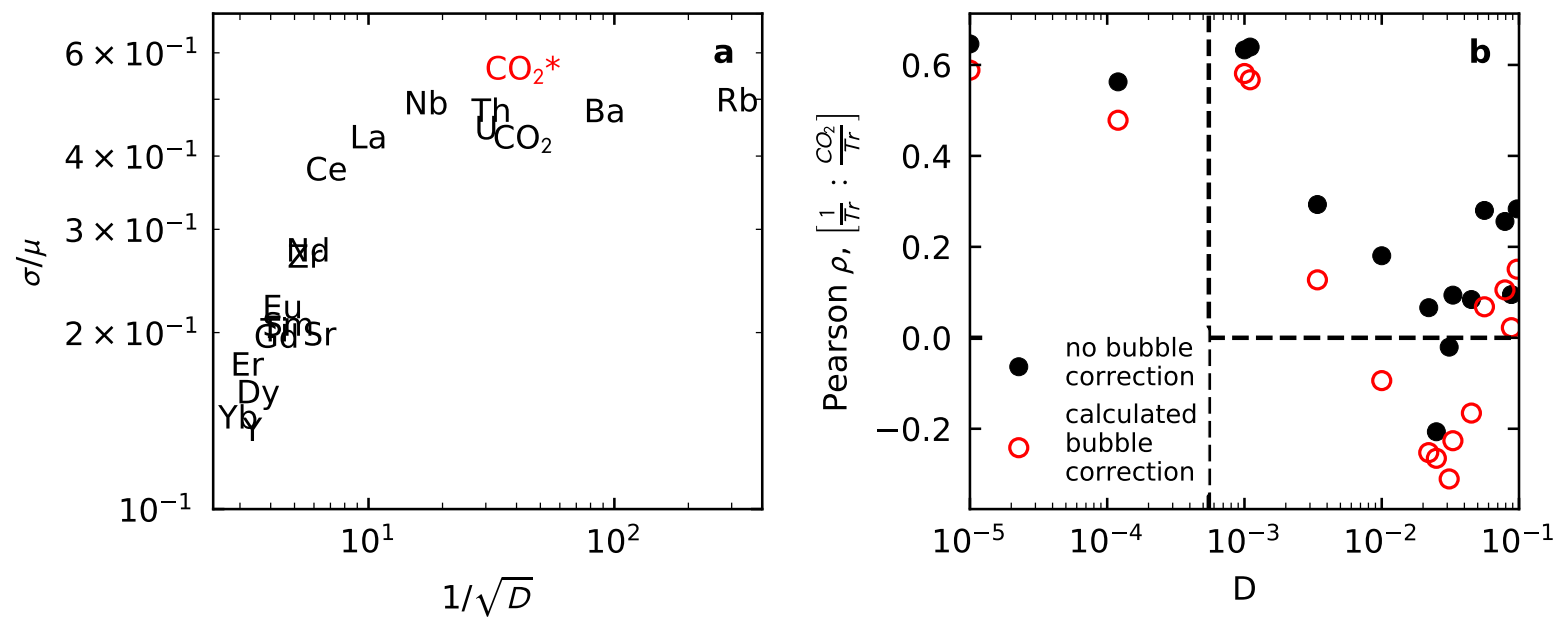

Figure A.1: Panel a shows the variance structure of the Borgarhraun dataset. The standard deviation normalised to the mean for each trace element is shown as a function of its partition coefficient (D) as reported by Workman and $\mathrm{Hart}_{\text {(2005). CO }}{ }^{*}$ indicates bubble-corrected $\mathrm{CO}_{2}$ concentrations. Panel b shows the Pearson correlation coefficient for $1 / \mathrm{El}$ vs $\mathrm{CO} 2 / \mathrm{El}$ (where $\mathrm{El}$ is a trace element), as used by Matthews et al. (2017). The vertical dashed line shows the partition coefficient of $\mathrm{CO}_{2}$ during melting as determined by Rosenthal et al. (2015).

where $C_{n}$ and $\left.C_{(} n-1\right)$ are the $\mathrm{CO}_{2}$ concentrations in the residual porosity after, and before the nth melting increment, respectively. This can be applied recursively to yield:

$$
\begin{gathered}
C_{n}=\left[\frac{\phi-d F_{n}}{\phi}\right]\left[\frac{\phi-d F_{n-1}}{\phi}\right] \cdots\left[\frac{\phi-d F_{1}}{\phi}\right] C_{0} \\
C_{n}=\frac{C_{0}}{\phi^{n}} \prod_{i=0}^{n-1} \phi-d F_{n-i}
\end{gathered}
$$

where $C_{0}$ is the $\mathrm{CO} 2$ concentration in the melt at the point of graphite exhaustion. Setting $d F_{n+1}=$ $d F_{n}=d F$,

$$
C_{n}=C_{0}\left(1-\frac{d F}{\phi}\right)^{n}
$$

and since:

$$
d F=\frac{\Delta F}{n}
$$

where $\Delta F=F-F_{\text {graphite-exhaustion, the concentra- }}$ tion at a given $\Delta F$ may be written:

$$
C(\Delta F)=C_{0}\left(1-\frac{\Delta F}{\phi n}\right)^{n}
$$

in the limit $d F \rightarrow 0$ and $n \rightarrow \infty$ :

$$
C(\Delta F)=C_{0} e^{-\frac{\Delta F}{\phi}}
$$

Examples of these calculations for variable $\mathrm{fO}_{2}$, are shown in Figure B.2. Graphite saturation during melting decreases the $\mathrm{CO}_{2}$ content of the most enriched melts, and increases the $\mathrm{CO}_{2}$ concentration in the more depleted melts. Since the degassing step substantially reduces the $\mathrm{CO}_{2}$ concentration of the most enriched melts in most runs of the model, the most pronounced effect of graphite saturation is on the depleted melts. Depleted melts generated from a very reduced melting region have extremely high $\mathrm{CO}_{2} / \mathrm{Ba}$ ratios (Figure B.3). Dissolution of $\mathrm{CO}_{2}$, exsolved from enriched melts, into undersaturated depleted melts will have the same qualitative effect on the $\mathrm{CO}_{2}$-trace element systematics.

Though graphite-saturated melting is unlikely to be important unless the mantle is significantly more reduced than indicated by $\mathrm{Fe}^{3+} / \Sigma \mathrm{Fe}$ ratios of Icelandic basalts (Shorttle et al., 2015), or MORB (Cottrell and Kelley, 2011; Berry et al., 2018), it is feasible that extremely high mantle $\mathrm{CO}_{2}$ concentrations may exert an influence on redox equilibria. Whilst the $\mathrm{CO}_{2}$-trace element systematics of Háleyjabunga and Miðfell rule out equilibrium with graphite for most of the melting region, it is not implausible that the most extreme values of $\mathrm{CO}_{2} / \mathrm{Ba}$ could be generated in this way. Significantly more melt inclusion analyses are required to fully characterise the high-tail of the $\mathrm{CO}_{2} / \mathrm{Ba}$ distributions. 


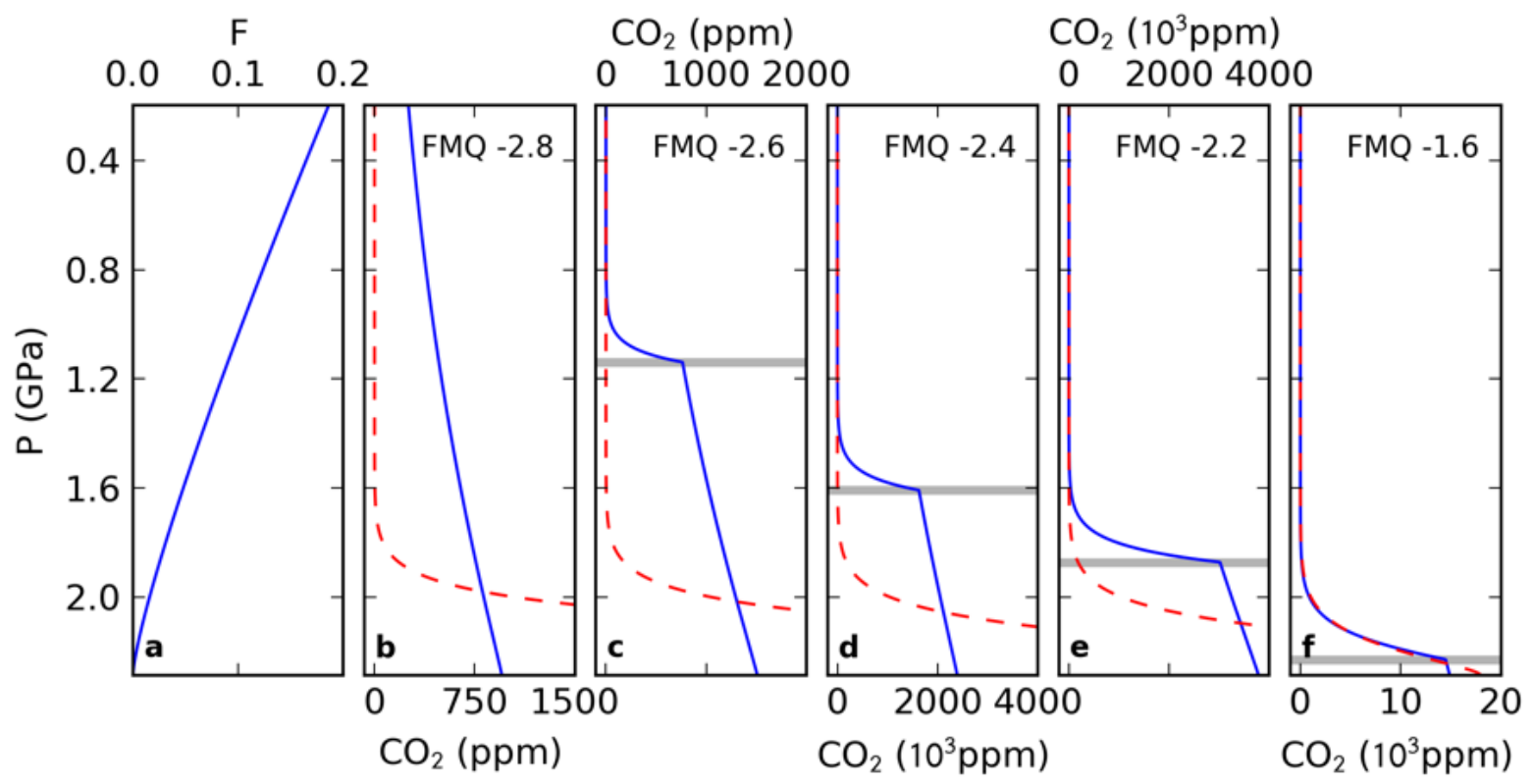

Figure B.2: Panel a shows the melt fraction as a function of pressure, calculated as described in the main text. The solid blue lines in panels b-f show the calculated $\mathrm{CO}_{2}$ concentration of melts generated at variable oxygen fugacity, buffered relative to the FMQ buffer. Below the grey line the mantle is graphite saturated. The red dashed line shows the concentration of $\mathrm{CO}_{2}$ in the melts in a mantle sufficiently oxidised that graphite is never saturated during melting, i.e. the result used in the main text of this paper. 

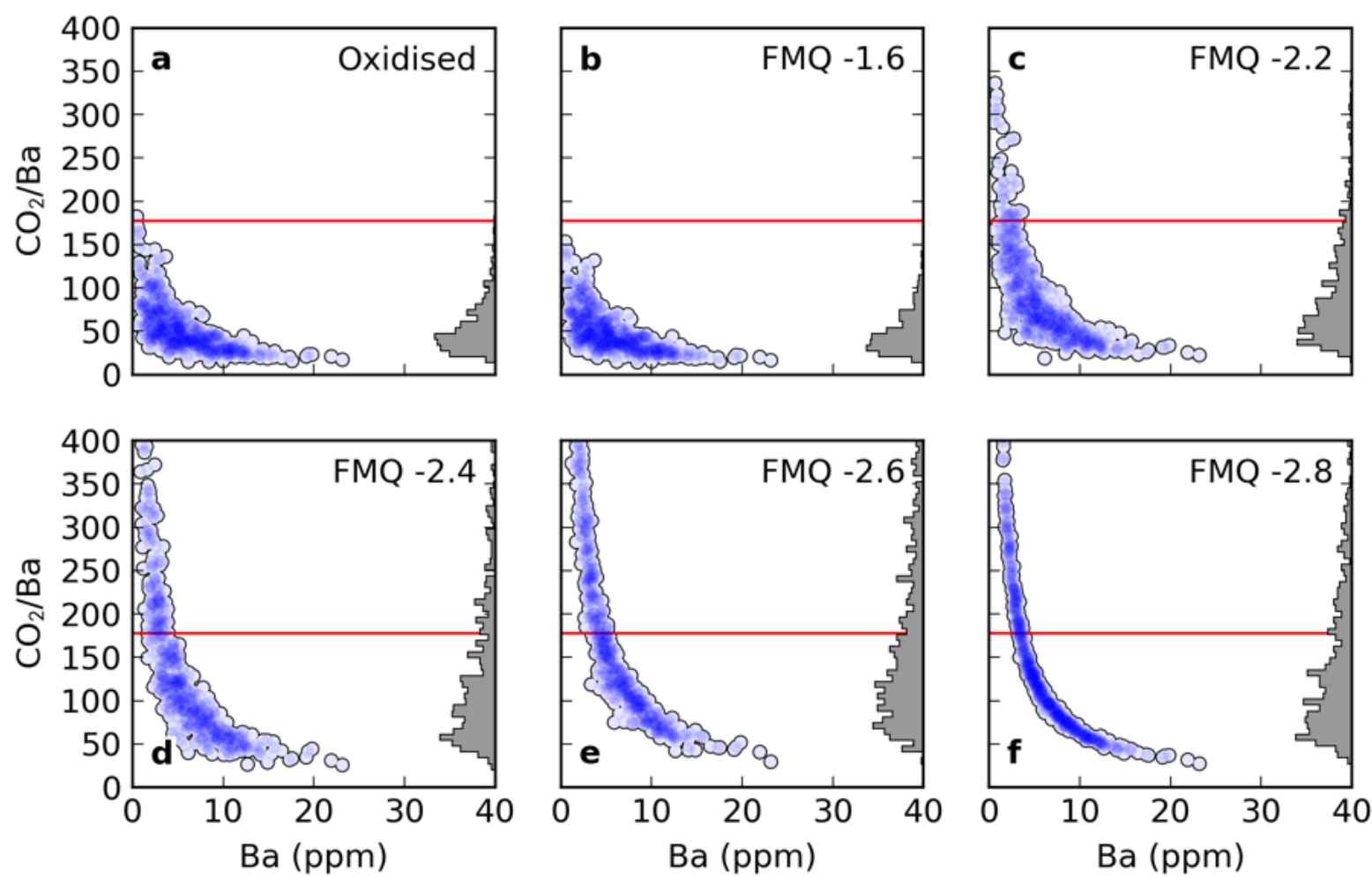

Figure B.3: Results of the mixing and degassing model for melts produced during graphite saturated melting (Error! Reference source not found.) and degassing at 2000 bar. The horizontal red and green lines show the source $\mathrm{CO}_{2} / \mathrm{Ba}$ ratio, and the ratio inferred from orthogonal-distance regression, respectively. The shading shows the degree of $\mathrm{CO}_{2}$ undersaturation in bars, at the pressure of degassing 